\title{
A Review of Online Partial Discharge Measurement of Large Generators
}

\author{
Yuanlin Luo ${ }^{1, *}$ (D), Zhaohui $\mathrm{Li}^{2}$ and Hong Wang ${ }^{3}$ \\ 1 School of Hydropower and Information Engineering, Huazhong University of Science and Technology, \\ Wuhan 430074, China \\ 2 State Key Laboratory of Advanced Electromagnetic Engineering and Technology, \\ Huazhong University of Science and Technology, Wuhan 430074, China; zhhli@hust.edu.cn \\ 3 Three Gorges Hydropower Plant, China Yangtze Power Corporation, Yichang 443002, China; \\ wang_hong2@ctg.com.cn \\ * Correspondence: ylluo_hust@hust.edu.cn; Tel.: +86-180-0717-7889
}

Received: 24 September 2017; Accepted: 22 October 2017; Published: 25 October 2017

\begin{abstract}
Online partial discharge (PD) measurements have long been used as an effective means to assess the condition of the stator windings of large generators. An increase in the use of PD online measurement systems during the last decade is evident. Improvements in the detection capabilities are partly the reason for the increased popularity. Another reason has been the development of digital signal processing techniques. In addition, rapid progress is being made in automated single PD source classification. However, there are still some factors hindering wider application of the system, such as the complex PD mechanism and PD pulse propagation in stator windings, the presence of detrimental noise and disturbances on-site, and multiple PD sources occurring simultaneously. To avoid repetition of past work and to provide an overview for fresh researchers in this area, this paper presents a comprehensive survey of the state-of-the-art knowledge on PD mechanism, PD pulse propagation in stator windings, PD signal detection methods and signal processing techniques. Areas for further research are also presented.
\end{abstract}

Keywords: large generator; stator winding insulation; partial discharge (PD); PD mechanism; propagation characteristics; signal detection methods; signal processing techniques

\section{Introduction}

The reliability and availability of large generators depends critically on the condition of their stator winding insulation, which is exposed to a combination of thermal, electrical, ambient and mechanical (TEAM) effects, i.e., ageing stresses, that contribute significantly to large generator failures [1,2], as shown in Figure 1. Partial discharge (PD) is known as both a main cause and an indicator of stator winding insulation deficiencies, and thus is efficient in indicating insulation latent defects and faults. PD measurements are more effective than most dielectric measurements when it comes to early detection of sudden faults, and have been applied with a considerable degree of success [3-5].

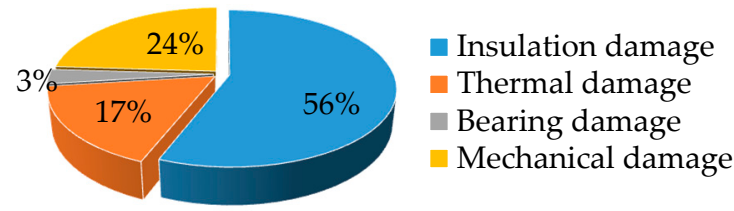

Figure 1. Failure statistics based on data presented in [1]. 
PD is a localized electrical discharge that only partially bridges the insulation between conductors, accompanied by charge movement, acoustic emission, light radiation and chemical reaction etc. [6]. Utilizing these physical characteristics of the PD processes, PD signals can be detected by many methods and systems, including electrical detection, acoustic detection, light detection and chemical detection method [6,7]. Among them, the electrical one is based on the measurements of electrical signals. It can either evaluate the global condition of insulation system by monitoring PD statistics or assess the most deteriorated site of the insulation through analysis of each PD pulse, and thereby has become the most prevalent detection method $[8,9]$ and the focus of the remainder of this paper.

PD online measurement consists of two key steps: PD signal detection and interpretation. The former can be implemented at the high voltage (HV) or neutral terminals of the generator with various sensors [7,9]. After that, the PD signal is processed by hardware and software techniques, including pre-processing by hardware modules, digitization, denoising by software-based techniques and subsequent PD source identification using feature extraction and pattern recognition techniques [9,10], as shown in Figure 2. Recently, an increase in the use of PD online measurement systems is evident [11-13]. Improvements in the detection capabilities are partly the reason for the increased popularity $[5,13,14]$. Another reason has been the development of digital signal processing techniques, including various software-based denoising techniques which improve the reliability of the measurement results in the presence of noise and disturbances. In addition, rapid progress is being made in feature extraction and single PD source classification [10]. However, the report [15] provided by International Council of Large Electric Systems (CIGRE) indicated that the increase is mostly caused by too many generators for limited skilled labor to manage. PD online measurement is still counted as "black magic" and best left to experts. In fact, in spite of the potentiality of PD analysis and the efforts to apply broadly this technology, it has not been developed as one would have expected after more than 60 years of PD measurement practices $[16,17]$. This is due in part to the complex mechanism of PDs and the propagation characteristic of PD in stator windings which make it a difficult task to select an appreciate detection location and sensor [4,9], as well as signal misinterpretation caused by detrimental noise and disturbances on-site which may be more frequent and of larger magnitude than the PD signals [9]. In addition, the fact that multiple PD sources may occur simultaneously makes it difficult to identify individual PD sources [13]. Thus, there is a perceived need to summarize PD research status on generators, including PD mechanism, PD propagation in stator winding, PD signal detection and insulation condition evaluation based on PD.

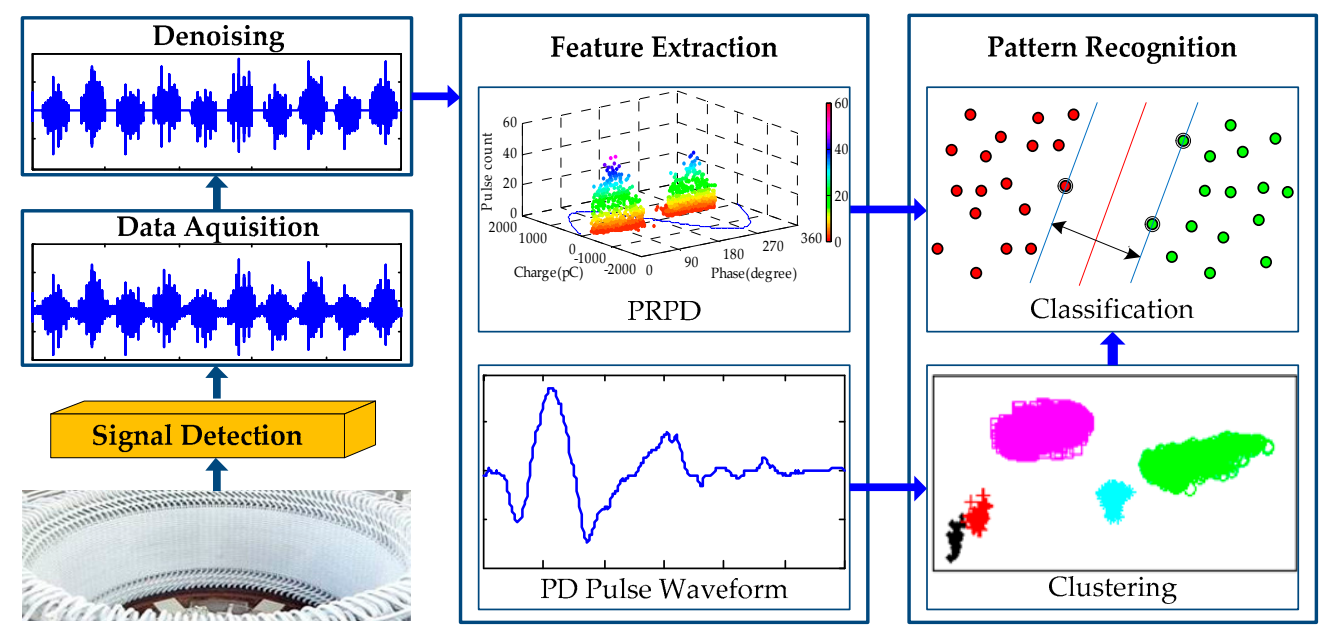

Figure 2. Flowchart of PD online measurement in large generators $[9,10]$.

Based on a comprehensive survey of PD theory and application, combined with the authors' work on test research and application on large generators during the last decade, this paper reviews online PD measurement in large generators over the past decades and highlights some concerns in 
current research and applications. Section 2 summarizes the mechanism of PD in large generators. From a survey of the research of PD signal propagation in stator windings, the major obstacles for the calibration and location of PD events are discussed in Section 3. Section 4 provides the details of the methods to detect PD at the high voltage (HV) terminals or neutral points of the generators, and summarizes the trends of PD signal acquisition. The PD signal denoising methods, feature extraction approaches and PD pattern recognition approaches are discussed in Section 5. Section 6 proposes some suggestions for improvement of PD online measurements. The conclusions of the present work are given in Section 7.

\section{Mechanism of PD in Generators}

\subsection{Types of $P D$}

PD is traditionally defined as a localized electrical discharge that only partially bridges the insulation between conductors [6], and includes internal discharge, slot discharge and end-winding discharge [9]. However, recent studies show that vibration sparking (VS) is more destructive to stator winding insulation and may occur at any position within a stator winding, while is scarcely known [18]. Unlike traditional PD, VS is due to combination of too low a resistance of the conductive slot coating and vibration of stator bar, whereby the former enlarges the circulating current flowing in the conductive coating, and the latter interrupts the current periodically and causes sparking [18]. Hence, this paper redefines PD as any electrical discharge endangering the stator winding insulation of generators, which results from the synergy of TEAM stresses, including traditional PD, VS and arcing. Arcing is an electrical discharge puncturing the dielectric between conductors, which is caused by poor electrical connections including cracked welding and broken conductors [9].

\subsection{Cause of PDs}

As the service life proceeds, generators are exposed to a combination of TEAM stresses which gradually reduce the strength of the stator winding insulation to the point when failure will eventually occur [14]. During that, various deterioration processes may act on the insulation deficiencies and yield PD. The root causes can be categorized as poor design and manufacture, transport and installation defects, and improper operation and maintenance [1,19], as shown in Table 1. In [20], Stone et al. presented the main aging and failure mechanisms of stator windings of large generators in detail.

Limited by technique level and insulating material characteristics, insulation deficiencies are inevitable during design and manufacturing, including defective corona suppression coatings, poor tightening of bars, inadequate resin impregnation, etc. To prevent slot PD or VS on the bar surfaces within slot portion, it is common practice to apply a partly conductive slot coating to the surface of the bars, which extends a few centimeters out of the slot exit and terminates with a silicon carbide coating overhang, i.e., stress control coating covering end-winding [21]. If they are not designed and manufactured properly, electrical slot PD or VS may be stimulated. In addition, bars are subjected to large electromagnetic forces during steady and transient states. If not tightened properly, stator windings may have a relative movement from the core and lead to an abrasion of insulation in the slot, which will cause mechanically-induced slot PD, or result in a decrease of space between overhang bars and then yield phase to phase PD, as well as arcing due to end cap welding cracks caused by vibration [20]. Furthermore, although manufacturing processes are designed to minimize internal voids, there are inevitably some voids during impregnation [9]. It is believed that early failures of the stator winding insulation can very often be attributed to poor design and manufacture [19].

Besides any design or manufacturing defect, the transport from the manufacturer to the user site and erection on-site may cause new and dangerous defects within insulation [8]. As already mentioned above, if not restrained properly during installation, bars will be loosened and discharge will be induced during operation. In addition, poor workmanship is the main cause of poor electrical 
connection, including poor brazing, poor soldering, or inadequately tightened bolted connections, which may lead to welding cracks and cause arcing, even under normal operating conditions.

Apart from the result of various design, manufacturing, transport or installation issues, most other deterioration processes are caused by TEAM stresses imposed on insulation during operation. Degradation mechanisms caused by operation and maintenance include ageing during normal operation, inappropriate or lack of maintenance and transient surges resulting from abnormal operation. During normal operation, the TEAM stresses act on the deficiencies and accelerate the ageing of insulation to a typical point when failure will eventually occur. One of the purposes of maintenance is to search and eliminate insulation defect. If lack of maintenance and left such defect untreated, it may cause surface tracking or other PDs. Furthermore, metal particles left by engineers during maintenance or resulted from generator components becoming loose during operation may lodge in vulnerable locations of the stator winding and then cause PD, such as phase-to-phase PD and end-winding corona [22]. Other than normal stresses, PDs can be stimulated by transient stresses caused by abnormal operation of the generator or the relevant devices, such as out-of-phase synchronization, power systems transients and/or abnormal external conditions $[1,14,19]$. Not surprisingly, in aged insulation systems, the final failure is likely to be stimulated by a mild transient stress that would not have been a problem in a new insulation system [20]. Therefore, the sudden PD caused by transient surges is the most critical one, demanding special attention. This is due to the fact that the sudden PD must be various types like arcing, phase-to-phase PD or slot PD as well.

\subsection{Characters of PDs}

Traditional PD generally results from locally enhanced electric fields at locations where the dielectric properties of insulating materials are degraded and cannot withstand against the electric field stress anymore, and thus occurs mainly at the HV end of stator windings [9]. However, due to specific design and manufacturing deficiencies, transport and installation defects, normal in-service ageing, or abnormal ageing, it may develop throughout the stator winding. Differing from that, arcing and VS are a result of the interruption of currents induced by the magnetic flux within the stator core, which may occur throughout the entire stator winding, and even in bars close to the neutral point [9].

Theoretical estimation and practical measurements have indicated that the frequency spectrum of a fast rise-time unipolar PD pulse contains DC to GHz signals [9]. However, due to the specific location, dielectric properties, electric field distribution and space charge caused by preceding PDs, the actual frequency content of a PD pulse may be part of that [4]. An experiment on realistic bars of a hydro generator conducted by Hudon et al. revealed the frequency content of different types of traditional PD signals [23], as shown in Table 1. Regarding the frequency content of arcing and VS, to the best knowledge of the authors, there are few publications on that. However, practical measurements suggested arcing has a strong component between $10 \mathrm{kHz}$ and $30 \mathrm{MHz}$ [24], while VS has a response peak at $6.7 \mathrm{MHz}$ [25].

PD pattern analysis is the most widely used PD interpretation approach aiming at identifying the root cause of PD in stator winding insulation, including pulse height analysis (PHA) [26] and phase resolved partial discharge (PRPD) [27]. There are many publications showing examples of the PD patterns of particular types of PD [23,28-30]. A rather special case is [23], where efforts were made to obtain patterns due just to one type of PD at a time, using multiple objects to confirm the patterns to be representative, as shown in Figure 3, where the phase angle of occurrence of the PD pulse is given along $x$ axis, along the other axis is the magnitude of the PD pulse. As regard to arcing and VS, there is no reference PRPD. However, since VS is driven by the magnetic flux, its PRPD will concentrate at current zero crossings of $0^{\circ}$ and $180^{\circ}$ (which should be near the voltage zero crossings), and manifest no polarity predominance [31]. 
Table 1. Characteristics of PDs in generators.

\begin{tabular}{|c|c|c|c|c|c|c|}
\hline \multicolumn{2}{|c|}{ Type $[9,20]$} & Cause $[1,9,18-21]$ & $\begin{array}{l}\text { Location } \\
{[9,20]}\end{array}$ & $\begin{array}{c}\text { Frequency/MHz } \\
{[23-25]}\end{array}$ & $\begin{array}{c}\text { Time to } \\
\text { Failure/Years } \\
{[20,21]}\end{array}$ & $\begin{array}{l}\text { Damage } \\
{[9,29,32]}\end{array}$ \\
\hline \multirow{3}{*}{ Internal PD } & Internal voids & poor manufacturing & \multirow{3}{*}{ HV winding } & \multirow{3}{*}{50} & $>30$ & Low \\
\hline & $\begin{array}{c}\text { Internal } \\
\text { delamination }\end{array}$ & $\begin{array}{l}\text { poor design \& } \\
\text { manufacturing }\end{array}$ & & & $<10$ & High \\
\hline & $\begin{array}{c}\text { Delamination } \\
\text { between conductor } \\
\text { and insulation }\end{array}$ & $\begin{array}{l}\text { poor design \& } \\
\text { manufacturing }\end{array}$ & & & $<10$ & High \\
\hline \multirow[t]{3}{*}{ Slot PD } & $\begin{array}{l}\text { Mechanically } \\
\text { induced slot PD }\end{array}$ & $\begin{array}{l}\text { poor design \& } \\
\text { manufacturing, } \\
\text { improper } \\
\text { maintenance }\end{array}$ & \multirow{3}{*}{$\begin{array}{l}\text { HV slot } \\
\text { winding }\end{array}$} & \multirow{3}{*}{100} & $<2$ & \multirow{3}{*}{ High } \\
\hline & Electrical slot PD & poor manufacturing & & & $>30$ & \\
\hline & $\begin{array}{l}\text { High intensity } \\
\text { slot PD }\end{array}$ & $\begin{array}{l}\text { poor design \& } \\
\text { manufacturing }\end{array}$ & & & $<1$ & \\
\hline \multirow{3}{*}{$\begin{array}{l}\text { End-winding } \\
\text { PD }\end{array}$} & $\begin{array}{l}\text { End-winding } \\
\text { corona }\end{array}$ & $\begin{array}{c}\text { poor design, } \\
\text { installation defect }\end{array}$ & \multirow{3}{*}{$\begin{array}{l}\text { HV overhang } \\
\text { winding }\end{array}$} & 500 & $>20$ & \multirow{3}{*}{ Normal } \\
\hline & Surface tracking & lack of maintenance & & 250 & $>10$ & \\
\hline & $\begin{array}{l}\text { Phase to phase } \\
\text { discharge }\end{array}$ & $\begin{array}{c}\text { poor design, } \\
\text { installation defect }\end{array}$ & & $250 \sim 500$ & $>5$ & \\
\hline \multirow{2}{*}{ Arcing } & Broken conductor & \multirow{2}{*}{$\begin{array}{c}\text { poor design, } \\
\text { installation defect }\end{array}$} & Slot exit & \multirow{2}{*}{$>30$} & \multirow{2}{*}{$<1$} & \multirow{2}{*}{ Very high } \\
\hline & Welding crack & & End cap & & & \\
\hline & VS & poor design & Slot winding & $>6.7$ & $<4$ & High \\
\hline
\end{tabular}

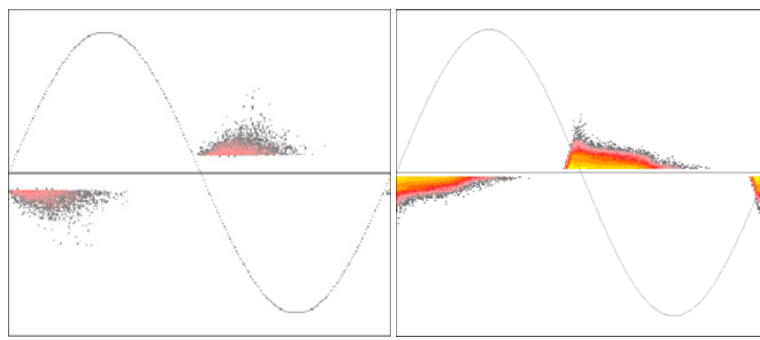

(a)

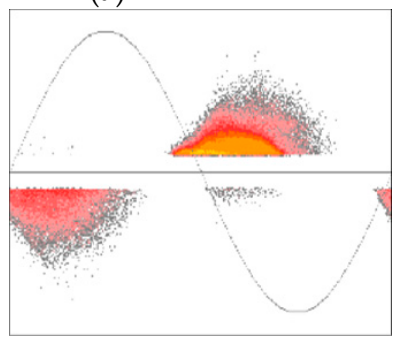

(e) (b)

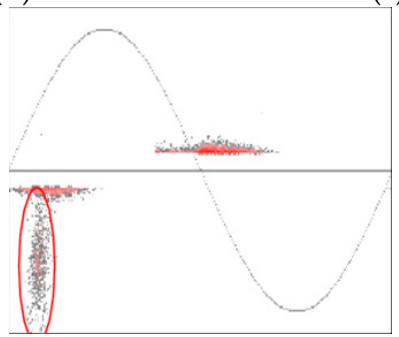

(f)

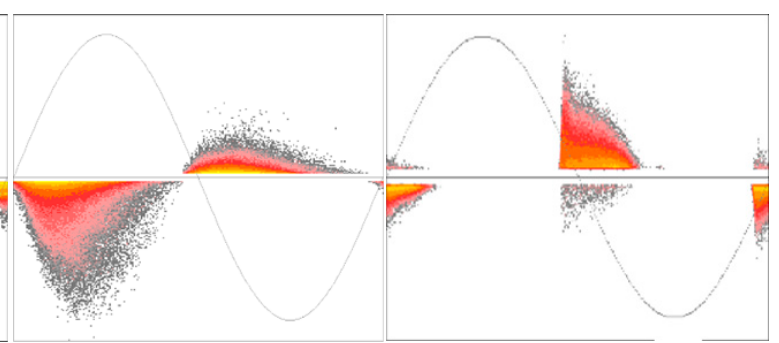

(c)

(d)

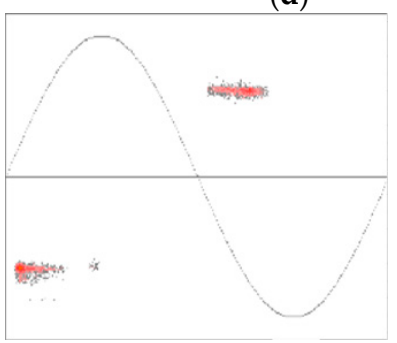

(g)

Figure 3. PD patterns in $[9,23]$ (a) Internal voids; (b) Internal delamination; (c) Delamination between conductor and insulation; (d) Slot discharge; (e) End-winding corona; (f) Surface tracking; (g) Phase to phase discharge.

\subsection{Risk of PDs}

The risk of PD depends on the typical deterioration acting on the insulation rather than just on how much damage the different types of PD are expected to cause. According to that, PD can be categorized in the descending order of energy and damage as arcing, sparking and traditional PD [9,29]. The risk associated with delaminations is given by [32] as "high", above all traditional PD sources other than slot PD, and followed by end-winding PD and internal PD. With regard to the time between onset of PD and final insulation failure, arcing is the shortest [20]. As a destructive mechanism, VS 
has sufficient power to cause insulation to fail rapidly [21]. As to traditional PD, slot PD is the fastest type, while end-winding PD and internal PD are relatively gentle [20]. The time to failure by phase to phase PD penetration of insulation is 5 years or more [20]. In the case of internal PD, the failure time associated with delaminations is usually less than 10 years [20]. As long as internal voids are small and do not significantly enlarge, internal void PD is negligible [9].

\subsection{Summary}

The last decades have seen a great advance in PD knowledge. Early research was biased towards the discharge in HV bars of a stator winding. With VS that occurs even in neutral parts of a stator winding now being widely discussed, having a generalized concept for PD has become even more important. That is why PD is generalized as an electrical discharge endangering the stator winding insulation of generators in this paper. Due to various insulation degradation mechanisms, the PDs in large generators vary in location, frequency feature and damage to insulation, as shown in Table 1. In order to monitor the insulation condition accurately, it is of vital importance to detect all the PDs, throughout the entire stator winding and frequency content as well as time of occurrence.

\section{Propagation of PD Pulse in Stator Winding}

Since it is impossible to measure a PD event directly, remote sensors will always record pulses that are influenced by the propagation along some distance from the PD origin. Therefore, it is essential to understand the effect of PD propagation on the measured PD event. In recent decades, much research work has been done and it was found that PD signals might propagate along several path in several modes accompanied by travelling waves, complex capacitive and inductive coupling, and resonance phenomena. Due to attenuation, distortion, reflection and cross-coupling of travelling wave signals, the shape and amplitude of the PD pulses recorded at the detection terminals differ from those at the site where they originate [9].

\subsection{Propagation Modes}

In 1985, Wilson et al. [33] found that PD pulses propagated through the stator winding by two modes, i.e., fast mode and slow mode. There is a strong distinction between fast mode of high frequency (HF, $3 \mathrm{MHz} 30 \mathrm{MHz}$ ), which travels to the terminals by shorter routes than propagation along the conductor path, and slow mode of low frequency ( $\mathrm{LF},<3 \mathrm{MHz})$, of which the transit time is proportional to the length of conductor between the PD site and detection terminals [33], as listed in Table 2. Along with Wilson, further experiments in [34,35] indicated that the two modes of PD pulse propagation in stator windings are frequency and generator dependent. The generator geometry determines the critical frequency at which the energy of the PD pulse is equally shared between the slow mode and fast mode [35]. However, the nature of the fast mode is contested anyway. It is said to be due to end-winding coupling in [33], but in [36] inductive coupling between bars of adjacent slots is expected, for frequencies even up to $20 \mathrm{MHz}$. In [34], the fast mode is thought to be capacitive coupling, while in [35] the authors wondered whether it is in fact due to displacement currents. It must be pointed out that the authors used a micro-rotating machine in [36], therefore it is still unknown whether the result is true for large generators or not. The critical boundary frequency between fast and slow modes is in the region of $1 \mathrm{MHz}$, whereas it is seen differently by different groups, and in some cases only the slow component is observed. There is a consensus that around $100 \mathrm{kHz}$ is the best frequency range for low attenuation of PD signals throughout the entire winding [33-35].

Table 2. Characteristics of Two Propagation Modes of PD Signal in Stator Winding [33].

\begin{tabular}{cccccc}
\hline Mode & Path & Distance & Frequency & Attenuation & Delay \\
\hline Slow mode & Conductor & Long & $<3 \mathrm{MHz}$ & Little & Increase with distance \\
Fast mode & Coupling & Short & $>3 \mathrm{MHz}$ & Critical & Negligible \\
\hline
\end{tabular}




\subsection{Cross-Coupling}

To obtain a better understanding of the fast mode, a comprehensive study was carried out by Wood et al. [37]. The results obtained on a $500 \mathrm{MW}$ turbine generator model showed that capacitive and inductive coupling in the end-winding were weak, the winding acted as a low-pass filter [37]. Meanwhile, a number of resonance frequencies between $40 \mathrm{MHz}$ and $100 \mathrm{MHz}$ were observed, which might shift lower when the PD pulse was deeper in the stator winding [37]. Differing from that, experiments conducted by $\mathrm{Li}$ et al. [38] showed obvious coupling between bars in the same slot or end-windings of adjacent slots. It should be noted that the frequency ranges exploited by Wood et al. [37] and Li et al. [38] are $35 \mathrm{kHz} 250 \mathrm{kHz}$ and $0 \sim 5 \mathrm{MHz}$, respectively. Thus the above results cannot accurately reflect the frequency characteristics of wide-band PD signals when propagating in stator windings.

To this end, Cheng and his colleagues performed a study on the propagation characteristics of different frequency ranges in a $50 \mathrm{MW}$ turbine generator with the rotor removed [39]. The results implied that signals below $2 \mathrm{MHz}$ transmit along conductors and attenuate rapidly, whereas signals between $2 \mathrm{MHz}$ and $12 \mathrm{MHz}$ couple through the end-winding capacitor network. The attenuation of signals between $2 \mathrm{MHz}$ and $6 \mathrm{MHz}$ is negligible, while that of $7 \mathrm{MHz} \sim 12 \mathrm{MHz}$ is significant and increases exponentially with the coupling distance between the PD site and the sensor [39]. For the tests, simulated PD pulses were fed in the end cap through an adhesive-backed tin foil injection electrode, which may not only cause LF attenuation and yield pulse strong dispersion, but also make that inputs at different end caps differ. Unfortunately, no thorough analysis was provided by the authors [39]. Along with the work of Cheng et al., Pemen et al. [40] modified the experiment by drilling a small hole in the insulation to directly feed signals to conductors. They verified the two propagation modes of PD signal in stator windings, and showed experimentally that the absence of end-windings prevents the fast mode, and thus denied the result derived from Tarver's experiment on micro-rotating machine in [36]. In addition, they presented the attenuation of two modes and the cross-coupling phenomenon caused by end-winding coupling quantitatively, as shown in Figure 4 . The experimental results obtained by Henriksen and Stone indicated that the pulse response was greatest in the phase where the PD occurs, when only the first peak of each pulse from three phase terminals was counted [41]. Further, results obtained by Pemen et al. suggested that, if the complete response including two modes of all four terminals could be measured and integrated, the measured apparent charge may not depend very much on the origin of the PD, and a proper calibration can be achieved [40]. However, limited by the test generator with only one bar in each slot, Pemen et al. only studied the coupling between end-winding of bars in adjacent slots, but not that between bars in the same slot. Recently, along with work of Pemen, Oslinger-Gutiérrez et al. [42] performed an experiment on a $2.4 \mathrm{kV} / 210 \mathrm{kVA}$ salient-pole synchronous machine, and verified the propagation modes and corresponding attenuation characteristics as well as cross-coupling between phases.

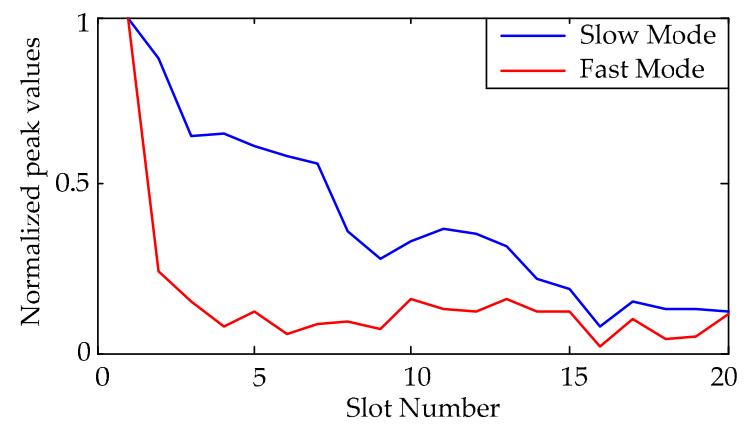

(a)

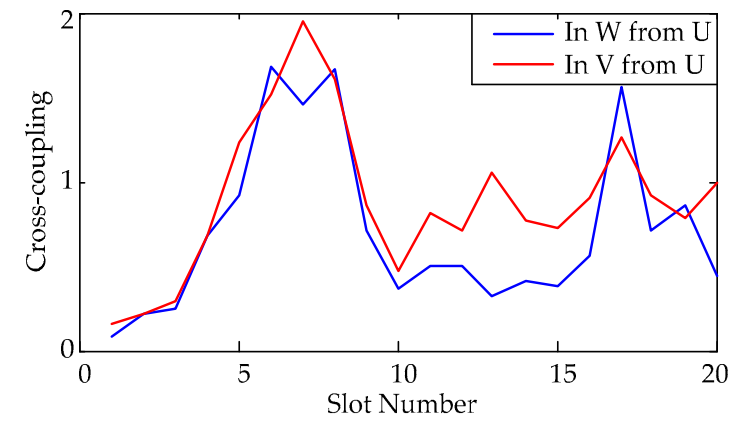

(b)

Figure 4. Propagation characteristics of PD signal in stator winding (a) Attenuation of fast and slow modes; (b) Cross-coupling from phase U to phase V and W, revised after [40]. 


\subsection{Summary}

The propagation characteristics of PD signals between the source and the sensor are a prerequisite not only for the detection frequency range determination, but also for the discharge calibration and source location. A number of workers in this area, e.g., Wilson et al. [33], Henriksen et al. [41], Gear et al. [34], Pemen et al. [40], have approached this problem from a variety of experimental and analytical points of view. However, despite increasing the basic understanding of what happens to a PD pulse as it propagates through a stator winding there is, as yet, no definitive theory to quantitatively describe the process.

The measured shape and amplitude of PD pulses depend on the location of the originating PD source, the distance to and position of the sensor, and the extremely complex propagation characteristics between them. These frequency dependent effects are related to the dimensions and geometry of the stator winding, it is impossible to directly and quantitatively link received signal strength of HF or very high frequency (VHF) PD signals to the actual charge level of the PD source, i.e., calibration [43]. In addition, it seems that by measuring the delay time between arrival of the fast and slow modes at the PD sensor, the relative distance to the PD site can be determined. Unfortunately, prior to this method can be used, the stator winding needs extensive testing/calibration where pulses are injected into different locations and the propagation delays are measured between the fast and slow modes, or on the other hand, a mathematical model is built.

\section{Detection of PD Signal}

To improve the sensitivity of PD measurements, great efforts have been made in PD online measurement during the last decades, and different techniques have been developed and they are in use for on-site applications. As described in the recently introduced IEC/TS 60034-27-2 [9] as well as the recently revised IEEE 1434 [7], all these techniques can be generally divided into neutral and HV terminal detection methods, in conjunction with sensors proposed by IEC, giving rise to four different configurations that are commonly used for making online measurements of PD.

\subsection{Neutral Detection Methods}

The neutral point of a generator is a good detection location not only because it has a low potential to ground, but also due to the fact that pulses caused by discharges at any location flow into neutral. The early pioneering work on PD detection in neutral point was done by Johnson and Warren, who detected the slot discharge pulses across the neutral grounding resistor which is not usual in practical occasions [16]. Nowadays, in lieu of a detection resistor, radio frequency current transformer (RFCT) and coupling capacitor were employed as PD sensors, as shown in Figure 5.

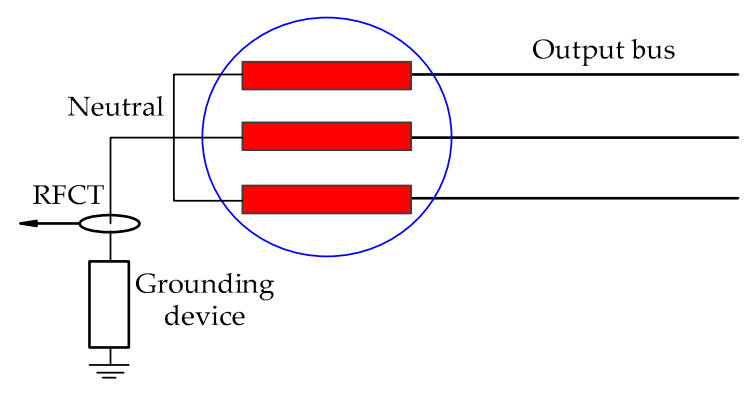

(a)

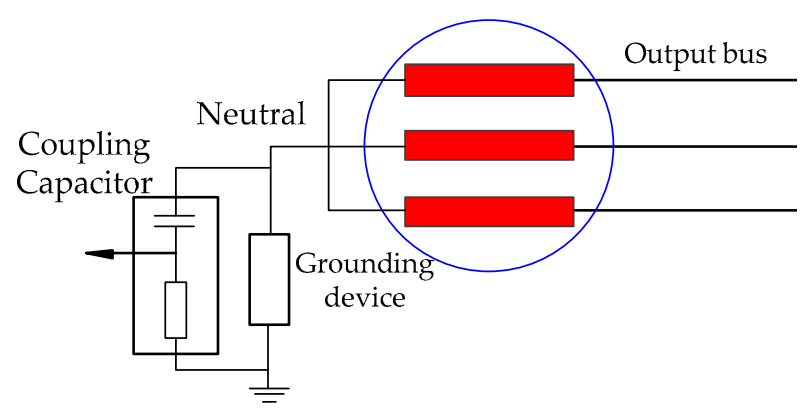

(b)

Figure 5. Neutral detection methods (a) Coupled by RFCT; (b) Coupled by coupling capacitor [44]. 


\subsubsection{Neutral RFCT Coupling (NCT)}

In 1979, Harrold and his colleagues [44] replaced grounding resistor used by Johnson and Warren [16] with a RFCT, locating at a convenient site on the lead connecting neutral and grounding transformer, to pick up discharge signals, as shown in Figure 5a, i.e., the NCT method. Restricted by computer technology and signal processing technique, NCT critically relies on the detection frequency range at earlier stage and consequently domain experience and expertise were required for selecting detection frequency range and distinguishing PD from noises. In addition, due to low sensitivity of RFCT and attenuation caused by neutral grounding transformer, NCT is only sensitive to severe PD. For these reasons, although demonstrated to be effective, the NCT has not been widely used in North America beyond the RFM [44]. In Europe, positive experience has been reported in [45], although supplementary coupling capacitors at the phase terminals were used to overcome the problems mentioned above. NCT has been applied in GDD [46] as well, as shown in Table 3.

Benefiting from galvanic isolation from generator, NCT is generator-safe, and has little impact on the operation reliability of generators under test. Nowadays, due to the attenuation characteristics of stator winding, NCT usually works below HF range to gain a high detection ability to the PDs throughout the entire stator winding, not only PD in bars adjacent to neutral, but also that in bars connecting to the HV terminal. However, it is difficult to deal with the mixed signals with serious noise and disturbance presenting in the detection frequency range. Recently, developing advanced signal processing techniques, such as noise reduction and pattern recognition techniques, mitigate these issues to some extent. In addition to that, research has been done to increase the sensitivity of RFCT for PD from all the likely parts of the stator winding to experience PD.

\subsubsection{Neutral Capacitor Coupling (NCC)}

To avoid the attenuation resulting from the neutral grounding transformer and consequently increase the detection sensitivity, Harrold et al. [44] proposed to replace RFCT with a coupling capacitor, which is in parallel with grounding transformer, to detect the discharge pulses. However, the proposal was not put into practice until 1989 when Mohammed and Mundulas replaced RFCT with a home-made capacitor, with its inner screen connected to neutral point and its outer screen grounding through a $2 \mathrm{k} \Omega$ detection resistor, and increasing the detection sensitivity by $40 \mathrm{~dB}$ [47]. Benefiting from the development of manufacturing technique, epoxy-mica insulated capacitor is widely used nowadays. A schematic setup of NCC is shown in Figure $5 b$.

NCC inherits the high reliability of NCT, and possesses higher sensitivity than the latter. Therefore, much attention from research institutes, universities and utilities has been paid to this method, and considerable success has been achieved, such as the NGC [11] and the HF-10 [48], as listed in Table 3. With the specific neutral detection point, the detection frequency range of NCC was similar with that of NCT, which can detect the PDs throughout the entire stator winding. Inevitably, the low signal to noise ratio (SNR) poses a critical challenge to PD signal interpretation and subsequent insulation condition assessment.

\subsection{HV Terminal Detecting Methods}

Before generator manufacturers moved away from the use of asphalt-based insulation systems to insulation systems utilizing epoxy resins, VS had not arose, thus close attention was paid to traditional PD. From the perspective of SNR of detection, HV terminal was preferred for PD signal detection, since traditional PD occurs mainly at the HV bars of windings. However, as more exposed than neutral to noise from transformer and power system, extra noise suppression might be necessary for HV terminal detecting methods. 


\subsubsection{HV Terminal Capacitor Coupling (HVCC)}

Kurtz et al. [49] modified the off-line test system described by Johnson [50] by replacing the large coupling capacitor with an appreciably smaller one of about $80 \mathrm{pF}$ connected with a resistive detection impedance, which was the predecessor of the subsequent PD analyzer (PDA), i.e., HVCC. PDA includes differential and directional modes. If an internal circuit ring with sufficient length exists, the best installation is a differential mode, as shown in Figure 6a. One coupling capacitor per line end of each parallel is installed and helps to separate PD from noise stemmed from outside generator by time of arrival and pulse characteristics $[49,51]$. When there is insufficient circuit ring to install coupling capacitors at least $2 \mathrm{~m}$ apart, a directional installation is required, as shown in Figure $6 \mathrm{~b}$ [51]. Two coupling capacitors are installed at output bus per phase, one as close as possible to the terminal and the other at least $2 \mathrm{~m}$ away towards transformer. The directional PDA utilized the delay lines in conjunction with a balanced PD detection circuit to separate external noise from internal PD. In addition, given output bus longer than $30 \mathrm{~m}$ or no significant noise present, it was possible to discard the capacitor $\mathrm{C} 2$ in Figure $6 \mathrm{~b}[51,52]$.

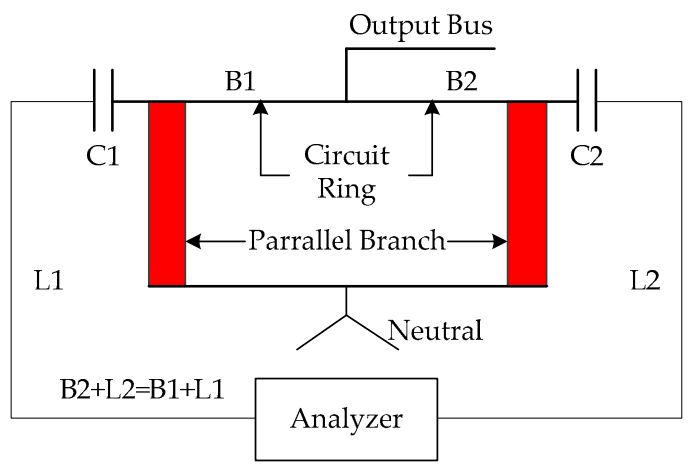

(a)

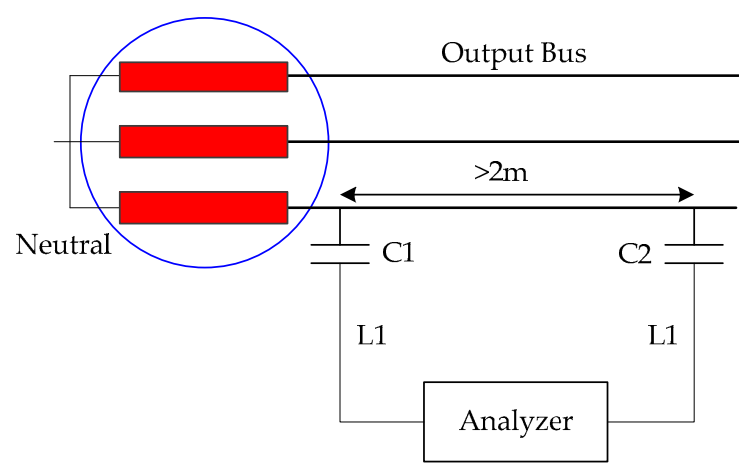

(b)

Figure 6. HVCC (a) differential PDA; (b) directional PDA [51].

A typical capacitor used for PDA is an $80 \mathrm{pF}$ epoxy-mica capacitor, with a detection frequency range of $40 \mathrm{MHz} 350 \mathrm{MHz}$ and a high SNR toward a small amount of winding. One supplier stated that only about $5 \%$ of bars of each phase near the HV terminal can be monitored by these capacitors [53]. Moreover, Zhu et al. [54] found that a capacitor with higher capacitance can detect more PD energy, thus being more sensitive to PD deep in stator winding. At present, typical capacitances for coupling capacitors used in HVCC are $80 \mathrm{pF}$ to $10 \mathrm{nF}$, as can readily be deduced in Table 3. Unlike NCC, the coupling capacitors of HVCC were directly connected to the HV terminal, which may cause a ground fault if failed. Thus, reliability of the capacitors are crucial, that's why the relevant IEC specification [9] and IEEE standards [7] highlight the requirements of the capacitors.

\subsubsection{HV Terminal RFCT Coupling (HVCT)}

In some cases, because of concerns with regard to the capability of stator winding insulation under the surge of steep-fronted switching transients, surge capacitors are installed between the phase terminals and ground. Unfortunately, they also short circuit the PD signals to ground, greatly reducing the effectiveness of PD measurements using HVCC. To face this problem as well as avoid measures directly attaching the insulation system of high voltage parts, natural detecting points as surge capacitors or the equivalent capacitor between bus bar and isolated phase output bus (IPB) sheath, as well as the capacitor between conductor and screen earth of cable (if existing) connecting the generator to the transformer are preferably used for access, as shown in Figure 7. A RFCT was placed on the grounding lead of these capacitors to detect PD signals $[11,48,55,56]$. Since these capacitors 
were adjacent to the bars likely to have traditional PD, much larger PD signals are expected in this location compared to the RFCT located at the neutral.

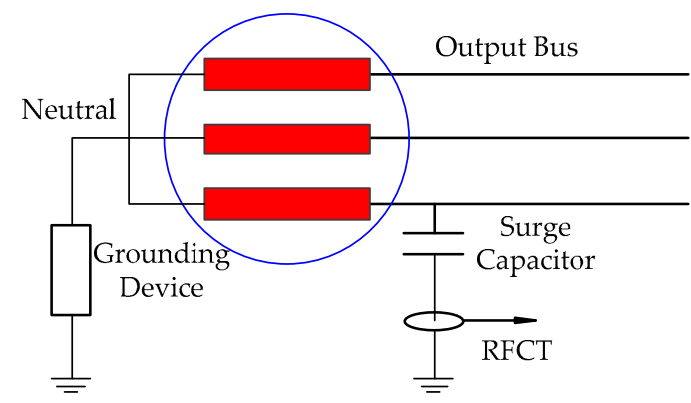

(a)

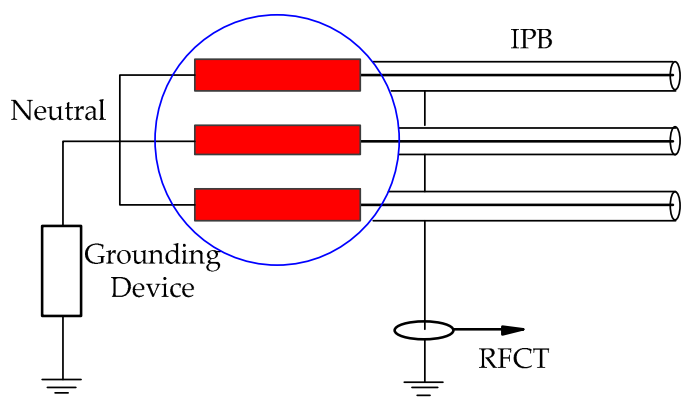

(b)

Figure 7. HVCT (a) Surge capacitor; (b) Equivalent capacitor $[48,56]$.

Table 3. Characteristics of a part of PD online measurement systems for large generators.

\begin{tabular}{|c|c|c|c|c|c|}
\hline $\begin{array}{l}\text { Detection } \\
\text { Point }\end{array}$ & Vender & Product & $\begin{array}{l}\text { Detection } \\
\text { Method }\end{array}$ & Sensor & Frequency Range \\
\hline \multirow{3}{*}{ Neutral } & Westinghouse [44] & RFM & NCT & $1 * \mathrm{RFCT}$ & $100 \mathrm{kHz} \sim 30 \mathrm{MHz}$ \\
\hline & $\begin{array}{c}\text { Monash } \\
\text { University [46] }\end{array}$ & GDD & $\begin{array}{l}\text { NCT } \\
\text { NCC }\end{array}$ & $\begin{array}{c}1 * \text { RFCT } \\
1 * 1000 \mathrm{pF} \mathrm{CC}\end{array}$ & $0 \sim 10 \mathrm{MHz}$ \\
\hline & $\begin{array}{l}\text { Hitech [11] } \\
\text { Siemens [48] }\end{array}$ & $\begin{array}{l}\text { NGC } \\
\text { HF-10 }\end{array}$ & $\begin{array}{l}\text { NCC + HVCT } \\
\text { NCC + HVCT }\end{array}$ & $\begin{array}{c}1 * 2 \mathrm{nFCC}+1^{*} \mathrm{RFCT} \\
1^{*} \mathrm{CC}+3^{*} \mathrm{RFCT}\end{array}$ & $\begin{array}{c}50 \mathrm{kHz} \sim 20 \mathrm{MHz} \\
300 \mathrm{kHz} \sim 20 \mathrm{MHz}\end{array}$ \\
\hline \multirow{4}{*}{ HV terminal } & $\begin{array}{l}\text { IRIS Power [51] } \\
\text { Doble [57] } \\
\text { Alstom [58] } \\
\text { OMICRON [59] }\end{array}$ & $\begin{array}{l}\text { HydroTracII } \\
\text { PDGuard } \\
\text { PAMOS } \\
\text { MONGEMO }\end{array}$ & $\begin{array}{c}\text { HVCC + NCC } \\
\text { HVCC + NCC } \\
\text { HVCC + NCC } \\
\text { HVCC }\end{array}$ & $\begin{array}{c}7^{*} 80 \mathrm{pF} \mathrm{CC} \\
4^{*} 1 \mathrm{nF} / 2 \mathrm{nF} \mathrm{CC} \\
4^{* 9} \mathrm{nF} \mathrm{CC} \\
3^{*} \mathrm{CC}\end{array}$ & $\begin{array}{c}40 \mathrm{MHz} \sim 350 \mathrm{MHz} \\
50 \mathrm{kHz} 20 \mathrm{MHz} \\
10 \mathrm{kHz} 10 \mathrm{MHz} \\
16 \mathrm{kHz} 30 \mathrm{MHz}\end{array}$ \\
\hline & HVPD [60] & Longshot & $\begin{array}{l}\text { HVCC } \\
\text { HVCT }\end{array}$ & $\begin{array}{c}3^{*} 500 \mathrm{pF} \mathrm{CC} \\
3^{*} \text { RFCT }\end{array}$ & $\begin{array}{c}1 \mathrm{MHz} \sim 50 \mathrm{MHz} \\
100 \mathrm{kHz} 20 \mathrm{MHz}\end{array}$ \\
\hline & Techimp [61] & PD Hub & $\begin{array}{l}\text { HVCC } \\
\text { HVCT }\end{array}$ & $\begin{array}{c}3 * \mathrm{CC} \\
3 * \mathrm{RFCT} \\
\end{array}$ & $16 \mathrm{kHz} 30 \mathrm{MHz}$ \\
\hline & PD System [62] & ICMmonitor & HVCC & $3^{*} \mathrm{CC}$ & $2 \mathrm{MHz} 20 \mathrm{MHz}$ \\
\hline
\end{tabular}

Restricted by signal processing technique, this method was used to detect noise by Campbell et al. [55], in conjunction with PD sensors to mask the noise by noise triggering. With the development of signal sensing technology and signal processing technique, due to the advance of high SNR for PD and high reliability of RFCT, HVCT has great research value and application potential, and has been put into practice on giant hydro generators recently [11]. For a larger amount of winding coverage, HVCT used a detection frequency range almost same with neutral detecting methods [11]. Thus, HVCT will face the same issues with neutral detecting methods.

\subsection{Data Acquisition}

Benefitting from great strides in insulation design and manufacturing, large generators tend to operate for more than 30 years before a rewind is needed. The various deterioration processes are mostly slow evolving. However, the corresponding failures are, for the most part, quite sudden and unfortunately, catastrophic. To minimize the risk of losing important information on PD, there is a pressing need of continuous PD online measurement [9].

Moreover, generators are unusual among HV equipment, they do not have specifications of acceptable PD levels, while the PD trend analysis is the most valuable tool for condition assessment. However, PDs in the generators strongly depend on the operation and ambient condition other than condition of the stator winding insulation. In addition, when a failure occurs, it is very important to collect all relevant information about the failure and make as much observations as possible on 
the failed generator in order to identify the causes. Hence, it's urgent to acquire simultaneously aforementioned condition parameters [9]. As a rule, many measurements which solve a problem provide the thread for a new one. The continuous acquirement of PD data and condition parameters may lead to a large amount of data, which cannot be stored indefinitely. Therefore, intelligent data reduction algorithms are needed, which automatically select the important PD data from the repetitive measurements and store them in a long-term database for later analysis [9].

\subsection{Summary}

The chance of false indications caused by noise and the amount of winding coverage for the stator winding are significant considerations when applying PD online measurements [13]. A lower frequency range PD system can detect PDs far away from the sensors, false negative indications may less likely, while is prone to false positive indication because of the presence of noise. A higher frequency range PD system offers a high SNR and few false positive indications, but could "see" only a comparatively short winding section near the sensors, thus easy to arise of false negative indication. Obviously, there is a trade-off between false positive indication (or SNR) and false negative indication (or winding coverage). The improved SNR is gained at the expense of loss of the amount of coverage of the stator winding, as contrasted in Table 4. A higher frequency range would produce results of which the sensitivity is biased towards the bars located closer to the sensor. Moreover, as mentioned above, the stator winding possesses a unique set of resonance frequencies in HF and VHF range. If the detection frequency range of the PD system coincides with one or more of these frequencies, then the PD magnitude measured will be anomalously high [43]. During last decade, the usage of PD system operating at lower frequency has been significantly promoted due to the development of understanding of propagation characteristics of PD signal in stator winding, as well as because of the progress in signal processing techniques, as shown in Table 3.

Table 4. Comparison of different detection frequency range $[6,9,63]$.

\begin{tabular}{ccc}
\hline Frequency Range & Advantages & Disadvantages \\
\hline LF $(<3 \mathrm{MHz})$ & $\begin{array}{c}\text { Full amount of winding coverage } \\
\text { Apparent charge calibratable } \\
\text { Good sensitivity }\end{array}$ & $\begin{array}{c}\text { Low SNR } \\
\text { Hard to location }\end{array}$ \\
\hline $\mathrm{HF}(3 \mathrm{MHz} 30 \mathrm{MHz})$ & $\begin{array}{c}\text { Large amount of winding coverage } \\
\text { High SNR } \\
\text { High sensitivity }\end{array}$ & $\begin{array}{c}\text { Apparent charge uncalibratable } \\
\text { Hard to location }\end{array}$ \\
\hline $\mathrm{VHF}(30 \mathrm{MHz} 300 \mathrm{MHz})$ & Very high SNR & $\begin{array}{c}\text { Small amount of winding coverage } \\
\text { Apparent charge uncalibratable } \\
\text { Very high sensitivity }\end{array}$ \\
\hline
\end{tabular}

\section{Analysis of PD Signal}

The main task of PD online measurement is to provide information, by analyzing PD pulse shape and PD pattern, as to whether PD occurs or not, and then identifying the PD types since not all PD may be equally harmful for insulation systems. It is widely recognized that there are close correlations between PD patterns and the source generating them [30], thus the PD source and the deterioration behind them can be identified by pattern recognition, which is indispensable for PD online measurement. However, the abundance of noise and disturbance, and the possible coexistence of multiple PD sources of various types within operational generators make fast and accurate PD measurement a highly complex task [13]. Therefore, noise suppression and PD pattern recognition are two important aspects in a PD online measurement system [64], as shown in Figure 2, where PD pattern recognition stage consists of two parts, i.e., feature extraction from denoised data followed by pattern recognition of the respective PD source. Of late, the focus of pattern recognition have shifted from single PD source classification to multiple PD sources separation, which is most prevalent in insulation systems of large generators during operation [65]. 


\subsection{Denoise}

One of the major challenges during PD online measurement performed in large generators is the inevitable emergence of noise and disturbance, which may be more frequent and of larger magnitude than the PD signal of interest. If cannot be adequately suppressed or accurately separated from PD pulses, they may be misidentified as PD, thus yielding false indications and reducing credibility of measurement results [13]. Therefore, review on types and features of noise and disturbance, and existing popular noise rejection ways via hardware and software is essential for developing reliable PD online measurement system of large generators. Extensive research has been carried out around the world for noise suppression, history of which is as archaic as the PD measurement systems themselves [16]. As the knowledge of PD and noise grew increasingly distinct, improvements were also sought in the field of noise elimination. According to the generation mechanism, noise can be suppressed through eliminating the sources, cutting off its coupling path and signal post-processing. The latter is the main focus of current research works and mainly falls into two categories: hardware-based denoising methods and software-based denoising methods.

\subsubsection{Types of Noise and Disturbance}

According to time-frequency (TF) domain characteristics, noise and disturbance can be broadly categorized as white noise (WN), discrete spectral interference (DSI), periodic pulse shaped interference (PPI) and stochastic pulse shaped interference (SPI) [66]. IEC/TS 60034-27-2 [9] defines noise as non-stator winding signals that clearly are not pulses, including WN and DSI, while disturbances are electrical pulses of relatively short duration and similar with stator winding PD pulses, including PPI and SPI.

In fact, most disturbances are stemmed from electrical components/equipment connected to the stator winding, and may indicate other defects beyond stator winding insulation that may cause failure, thus should be coped with as signal rather as disturbance $[9,48]$. Therefore, attention of current denoising research is focusing on rejecting noise, i.e., WN and DSI. Disturbances are separated from PD pulses by pattern recognition techniques after denoising [67]. Finally, the schematic setup of PD online measurement system in Figure 2 can be extended as seen in Figure 8.

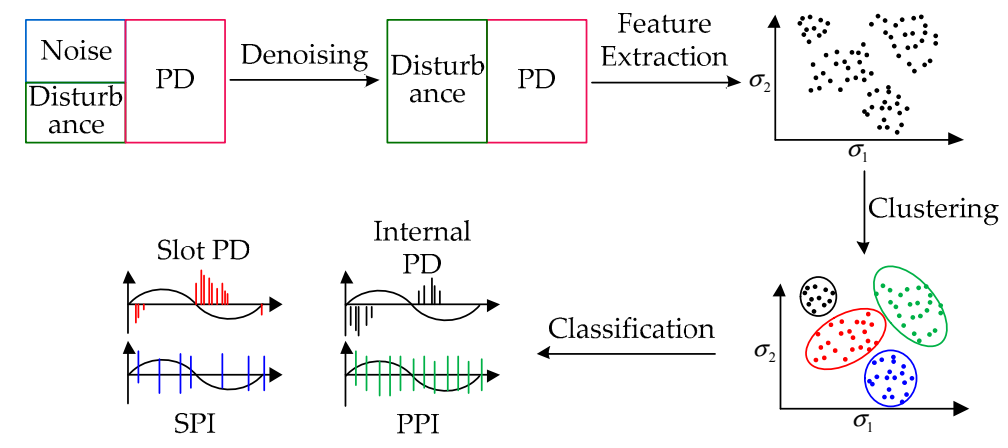

Figure 8. PD signal processing procedure [9].

\subsubsection{Hardware-Based Denoising}

Since the problem of noise was recognized in PD online measurement, extensive research work has been pursued and three basic hardware-based approaches have been developed. These include hardware filtering, noise gating and balanced circuit.

The idea behind hardware filtering is that the frequency spectrum of noise is different from that of PD pulse, thus it is mainly used to suppress DSI. In addition, typical frequency range at which the noise is negligible, was selected to improve SNR [44]. Currently, hardware filters are widely applied in PD measurement systems to increase the SNR and decrease quantization error of subsequent digitization by an analog to digital converter (ADC), and help anti-aliasing as well. 
For disturbances occurring at stable phase or regular intervals, noise gating is efficient in blocking them through a gate or window which can be opened or closed at typical moments. Furthermore, to increase the flexibility of this method, a dedicated noise sensor placed close-by a known source of noise was introduced to trigger the open-close of the gate, which would open only if detecting noise above preset threshold, and then stop data acquisition until noise disappeared [46]. Whereas this method is effective only for case of known source of noise, and crucially depends on preset noise threshold. Moreover, the true PD signal will be lost when occurring with noise simultaneously.

Noise suppression by the balanced circuit or the use of two sensors in differential mode has been well developed and widely used in PD measurement [49,51], as illustrated in Figure 6. Based on the specific location of two sensors, it's valid to identity signals from internal or external of the generators. However, using this method, the measurement system must operate in HF or VHF to capture the pulse waveform with reasonable fidelity, and yet cannot remove disturbance stemming from generators themselves, such as those from a static excitation systems or from the flexible links connecting the generator terminals to the IPB [51].

\subsubsection{Software-Based Denoising}

As discussed above, it very difficult to reject all noise and disturbance by using existing hardware-based denoising methods alone. Fortunately, advances in computer science, together with recent progress made in signal processing techniques lead to an extensive exploration and development of software-based denoising methods. The inspiration for these methods lies on the basis of that noise has different characteristics with PD signal in time or frequency domain. These methods can be broadly categorized as time-domain methods, frequency-domain methods and TF domain methods.

At the beginning of PD online measurement in large generators, the time-domain methods were used to remove the noise in detected signal. From aspects of statistical and waveform analysis, various methods have been explored and utilized in practical application. In [68], given that the noise are less than PD, they simply disregard signals less than $10 \%$ of the maximal discharge. However, this method relies on a pasteboard basis, thus it is not applicable for practical application which requires good accuracy. In order to reduce the relative level of noise and improve the detection SNR, the moving averaging technique was employed by practitioner in the field [6]. But due to memory propagation effect, PD pulsea may not recur at same phase in each cycle of applied voltage [69], thus it may yield distortion after moving averaging. The study of PD propagation characteristics in Section 3 found that the farther the signal source, the longer the detected pulse rise time will be. Thus the pulse rise time and duration are effective features to separate noise from PD [70]. In addition, the pulses from the same source will travel along the same path, thus they must be highly similar in waveform and different from other sources. Therefore, disturbances can be separated from PD based on waveform analysis in combination with pattern recognition which is a focus of present research [71].

Besides time-domain methods, frequency-domain denoising methods were extensively studied and utilized, especially on DSI removal. In general, the frequency-domain denoising is realized through Fourier analysis and filtering. Fast Fourier transform (FFT) is the most popular Fourier analysis method applied in PD online measurement. Based on the power spectrum density (PSD) of detected signals obtained by FFT, in conjunction with threshold optimized by fuzzy C-mean (FCM) adaptively, Luo et al. [72] proposed an extractive method by searching DSI frequencies in PSD and compensating these frequencies smoothly with a compression ratio, which outperforms the wavelet-based denoising methods. As regard to filtering, there are several filters have been employed to suppress the PD signals, such as infinite impulse response (IIR) filter, finite impulse response filter, notch filter [73] and adaptive filter [74]. In [73], Nagesh et al. evaluated various types of digital filters based on pulse distortion and filtering time, and found the cascaded 2nd order IIR lattice notch filter outperformed the others in DSI removal. However, the filterers face difficulty in determining the frequency of disturbance and demerit of time-consuming, and may cause pulse attenuation and thus waveform distortion, which hampers subsequent PD pattern recognition. 
It is obvious that time-domain methods cannot reject disturbances when overlapped on the PD pulses, while frequency-domain methods cannot suppress noise or disturbance when its frequency spectrum overlaps with that of PD signal. Thus TF domain denoising is of paramount importance for those cases. Due to unique ability of identifying singularity signal in both time and frequency domains, the wavelet transform is efficient in noise reduction. The wavelet thresholding denoising involves three steps, i.e., decomposition, thresholding and reconstruction. During that, three major problems were mother wavelet selection, decomposition level determination and threshold rule determination. Initially, wavelet denoising is typically conducted based on expertise of the operators [66]. To improve the automation and performance, great efforts have been made, various optimal mother wavelet selection methods have been proposed in the literature, such as correlation based [75,76], energy-based [67,77] and SNR-based approaches [77,78]. The determination of decomposition level was mainly on the basis of prior knowledge of the distribution of the signal energy in wavelet domain. It was made arbitrarily or through trial and error in previous studies [66]. An automatic approach was introduced in [79], where maximum decomposition level was set to that corresponding to the most informative sub-band. As well, references $[77,78]$ introduced an energy ratio threshold-based method to determine the minimum decomposition level, which can retain significant energy of signal as well avoid excessive computational cost. To generate better results, the threshold rule is the last but hardest barrier. The universal threshold, SURE threshold, minimax threshold and empirical threshold have been proved effective in PD denoising. However, these thresholds crucially rely on the expertise of operators, and are thus only semi-automatic and inapplicable for online measurement applications. To this end, Ma et al. [75] proposed an automated thresholding method which is decomposition level dependent. In [80], Zhang et al. introduced a novel threshold determination method based on a nonenergized reference object which may not generate any PD, the reference object best immediate vicinity of equipment under test. Then the signal recorded on the reference object is decomposed by selected wavelet to certain level, the absolute maximum coefficients of each level are selected as threshold of this level for PD signal denoising.

Recently, complex wavelet transform [81] and cross wavelet transform (CWT) [82] were introduced as extension of wavelet transform. Compared with discrete wavelet transform (DWT), complex wavelet transform is shift invariant and possesses greater directional selectivity. Cross wavelet transform is valuable in analyzing TF correlation and phase relation between two signals. In [82], cross wavelet transform has been used to combine the tasks of noise suppression and feature extraction and implement two tasks in a single step. Apart from various wavelet transform, ensemble empirical mode decomposition [83] and sparse representation [84] are also utilized to noise reduction with considerable degree of success.

However, the disadvantage of all software-based denoising techniques is that the signal needs to be digitized. If the noise and disturbance are of larger magnitude than the PD signal, the digitized values for PD are quite small compared to the least significant bit of the ADC. Therefore, the hardware-based denoising module is indispensable to suppress strong noise and disturbance before digitization. In [85], 32 different types of denoising techniques, such as FFT threshold filter, notch filter and wavelet denoising, were compared and the results showed that the combination of wavelet and notch filter performed better for WN and DSI suppression.

\subsubsection{Summary}

Noise and disturbance can couple with PD online measurement systems from several kinds of sources in different ways and with different features. Therefore, noise rejection has not yet a unique solution and is best implemented by synthesizing several techniques, each of them tailored for a specific kind of noise or disturbance. Table 5 summarizes all types of noise and disturbance comparing their unique characteristics, sources and the denoising methods utilized by researchers effectively. However, due to the diversity of noise and disturbance, as well as the PD measurement system, denoising methods are not perfect and there is no universal denoising standard. There is a continuous need to 
study the PD mechanism as well as PD signal propagation characteristics in a more comprehensive and in-depth manner.

Table 5. Comparison of different noise and disturbance $[9,32,66,80,85]$.

\begin{tabular}{|c|c|c|c|c|}
\hline Typ & & Characteristics & Source & $\begin{array}{l}\text { Denoising } \\
\text { Techniques }\end{array}$ \\
\hline \multirow[b]{2}{*}{ Noise } & WN & $\begin{array}{l}\text { 1. PSD is constant } \\
\text { 2. continuous signal }\end{array}$ & $\begin{array}{l}\text { 1. hardware thermal noise } \\
\text { 2. ambient noise }\end{array}$ & Wavelet denoising \\
\hline & DSI & $\begin{array}{l}\text { 1. narrow band spectrum } \\
\text { 2. continuous signal }\end{array}$ & $\begin{array}{l}\text { 1. harmonic signal } \\
\text { 2. carrier communication } \\
\text { 3. AM/FM radio }\end{array}$ & $\begin{array}{l}\text { Hardware filter } \\
\text { Notch filter }\end{array}$ \\
\hline \multirow[b]{2}{*}{ Disturbance } & PPI & $\begin{array}{l}\text { 1. broad band spectrum } \\
\text { 2. periodic and narrow signal }\end{array}$ & $\begin{array}{l}\text { 1. excitation systems } \\
\text { 2. power electronics }\end{array}$ & \multirow{2}{*}{$\begin{array}{l}\text { Noise gating } \\
\text { Balanced circuit } \\
\text { Pattern recognition }\end{array}$} \\
\hline & SPI & $\begin{array}{l}\text { 1. broad band spectrum } \\
\text { 2. stochastic and narrow signal }\end{array}$ & $\begin{array}{l}\text { 1. breaker operation } \\
\text { 2. lighting } \\
\text { 3. other HV equipment }\end{array}$ & \\
\hline
\end{tabular}

\subsection{Feature Extraction}

Feature extraction is the fundament of pattern recognition, and the recognition time can be significantly lessened by minimizing the number of distinguishing feature parameters. In general, PD signals can be represented in two different patterns, i.e., time-resolved pulse waveform and phase-resolved PD distribution, as depicted in Figure 9. Figure 9a shows a PD pulse $q$ - $t$ waveform, where $q$ is the pulse amplitude in $\mathrm{mV}$ and $t$ is the corresponding time in $\mu$ s. Figure $9 \mathrm{~b}$ shows a typical $\varphi-q-n$ pattern, in which $n$ is PD pulse repetition rate or pulse count in typical phase window over a selected time duration, $q$ represents the charge transfer in $\mathrm{pC}$ or magnitude in $\mathrm{mV}$ of each PD pulse and $\varphi$ indicates the phase angle of occurrence of the PD pulse [6]. By using these PD data patterns, two different types of feature extraction approaches have been developed, namely, statistical analysis method and time-domain analysis method.

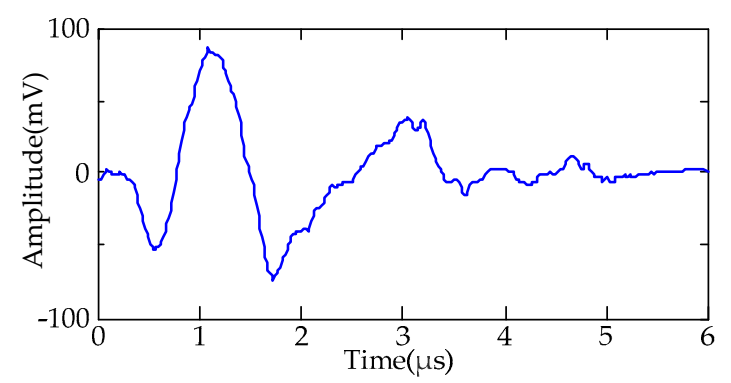

(a)

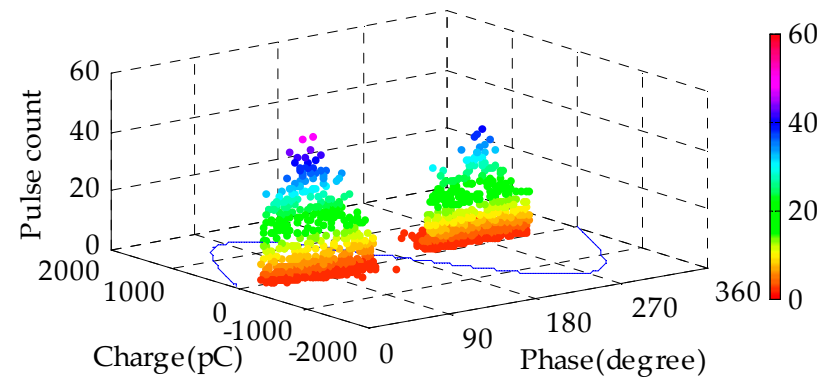

(b)

Figure 9. PD data patterns (a) PD pulse waveform; (b) PD PRPD pattern.

\subsubsection{Statistical Analysis Methods}

This type of feature extraction methods are mainly based on PD distribution, including PHA and PRPD. The latter consists of $\varphi-q-n$ 3D bivariate distribution, and 2D univariate distribution such as max charge $q_{m}$ versus $\varphi$, average charge $q_{a}$ versus $\varphi$ and $n-\varphi$ [27]. Due to the wide usage in visual display of PD distribution, earlier research focused on extracting features from the profile or gray image of these distributions, and have achieved great success in single PD source recognition.

\section{Statistical Moment}

As pioneers of PRPD analysis and computer-based PD measurement, Okamoto and Tanaka first introduced statistical moment, i.e., skewness, to characterize the $q_{a}-\varphi$ distribution by a computer in 1986 [86]. Along with them, Gulski et al. performed a more comprehensive study on the statistical 
moments of different PD distributions, including mean $\mu$, variance $\sigma^{2}$, skewness $S_{k}$, kurtosis $K_{u}$ of the positive and negative half cycles of $n-\varphi$ and $\eta_{a}-\varphi$ distribution profile, as well as cross-correlation factor $c c$ between two halves [68]. These statistical moments defined as Equations (1)-(5):

$$
\begin{gathered}
\mu=\sum_{i=1}^{N} x_{i} f\left(x_{i}\right) / \sum_{i=1}^{N} f\left(x_{i}\right) \\
\sigma^{2}=\sum_{i=1}^{N}\left(x_{i}-\mu\right) f\left(x_{i}\right) / \sum_{i=1}^{N} f\left(x_{i}\right) \\
S_{k}=\sum_{i=1}^{N}\left(x_{i}-\mu\right)^{3} f\left(x_{i}\right) / \sigma^{3} \sum_{i=1}^{N} f\left(x_{i}\right) \\
K_{u}=\sum_{i=1}^{N}\left(x_{i}-\mu\right)^{2} f\left(x_{i}\right) / \sigma^{4} \sum_{i=1}^{N} f\left(x_{i}\right)-3 \\
c c=\left(\sum_{i=1}^{N} x_{i}^{+} x_{i}^{-}-\sum_{i=1}^{N} x_{i}^{+} \sum_{i=1}^{N} x_{i}^{-} / N\right) / \sqrt{\left[\sum_{i=1}^{N}\left(x_{i}^{+}\right)^{2}-\left(\sum_{i=1}^{N} x_{i}^{+}\right)^{2} / N\right]\left[\sum_{i=1}^{N}\left(x_{i}^{-}\right)^{2}-\left(\sum_{i=1}^{N} x_{i}^{-}\right)^{2} / N\right]}
\end{gathered}
$$

where $x_{i}$ is a specific feature value of the $i_{\text {th }}$ phase or amplitude window, $N$ is the window number, and $f(x)$ is the function of PD distribution curve. These statistical moments were efficient in characterizing PD distributions derived from different PD sources, therefore they are of great importance in single PD source recognition and thus become the most prevalent recognition feature. In addition, a study conducted by Mas'ud et al. [87] demonstrated that there existed statistical distinction for different phase window size and amplitude window size on some of the statistical moments, thus a special care has to be taken to maintain these window sizes for the consistency of PD pattern recognition.

\section{PCA for PD Distribution}

Apart from statistical moments, features used to depict the PD distribution profile can be achieved by dimensional reduction techniques, such as principal component analysis (PCA) and stochastic neighbor embedding (SNE). All the approaches [88-90] used PCA to extract features and reduce dimensionality. Their difference is at the PD patterns used for extraction. In [88], the PD signals were represented by $n-\varphi, q_{a}-\varphi$ and $q_{m}-\varphi$, Ma et al. extracted seven principal components by PCA as well as seven elements by SNE to form the features set. Besides above 3 PD patterns, a new average discharge current $i$ versus $\varphi$ was introduced by Lai et al. [89] for feature extraction by PCA. Differing from that, Raymond et al. [90] first split the $n-q-\varphi$ profile into six groups, including negative and positive discharge groups and four phase quadrants groups. Then PCA was performed on these groups separately, and the first two principal components of each group were combined to form the features set. In addition, the authors compared the performance of features extracted by PCA, statistical moments and fractal features under different level of noise, and found that the feature extracted by PCA had significantly better noise tolerance than two others [90].

\section{Image Features}

The starting point of the above methods is to extract features which are efficient in charactering PD distribution profile, while the image attribute of PD distribution is neglected. In recent decades, some scholars have studied the characteristics of PRPD image, and many modern image processing techniques are used to extract the distinguishing features of the image [91-94]. PD is a natural phenomenon arising inside insulation systems, and realizes a complex 3D PRPD image. In [91], motived by the capability of fractal theory of modeling the complex images, the authors used two fractal parameters, fractal dimension $D$ and lacunarity $\Lambda$, to represent the 3D PRPD image. In [92,93], the authors used 2 dimension PCA (2DPCA) to decomposing $q_{a}-\varphi$ gray image into various vectors on horizontal and vertical directions, respectively, and extracted nine features for each vector, such as 
mean value and standard deviation, to form three feature sets for horizontal, vertical and assembled vectors, respectively. Then non-dominated sorting genetic algorithm II (NSGA-II) based feature selection technique was adopted to reduce the feature dimension and further improve the recognition performance and generalization ability of the features [93]. In [94], three level multi- resolution signal decomposition (MSD) was applied to decompose the PRPD image, and horizontal and vertical images were reconstructed at the third level. Since these two images were found to contain the necessary discriminating information regarding individual PD sources through visual inspection. To this end, the authors proposed to form a suitable feature vector by averaging the two images in the magnitude and phase directions, respectively. To reduce feature dimensions, nearest-neighbor interpolation was performed on averaged vectors. Further, the final feature vector was formed by concatenating the averaged phase and magnitude vectors.

4. Weibull Parameters

These aforementioned features are efficient for the case of single PD source. However, due to the presence of various defects, more than two PD sources may simultaneously occur in the complex epoxy-mica insulation system of large generators. To this end, given the probability density function of PHA curve can be represented by Weibull function:

$$
F(q ; \alpha, \beta)=1-\exp \left[-\left(\frac{q}{\alpha}\right)^{\beta}\right]
$$

where $\alpha$ and $\beta$ are the scale and shape parameters, $q$ is the PD pulse amplitude. Cacciari proposed to character the mixed PHA of two discharge source by a 5-parameter mixed Weibull distribution, and tried to identify two discharge sources by feature composed of these five parameters [95]. However, despite the fact that the PHAs of two distinct PD sources may be quite the same or very similar, these features perform well only if the PHAs of two PD sources are not completely overlapping. Take this into consideration, Candela et al. [96] proposed a hybrid approach which uses a synthesis of two Weibull parameters $(\alpha$ and $\beta)$, two statistical moments $\left(K_{u}\right.$ and $\left.S_{k}\right)$ and two fractal parameters $(D$ and $\Lambda)$ as input feature of neural network, to perform multi PD source classification with high precision.

\subsubsection{Time-Domain Analysis Methods}

In practical scenarios, multiple PD or disturbance sources may act simultaneously and each PRPD pattern will superimpose on the global PRPD pattern. Therefore, despite great progress made on feature extraction methods encompassing PRPD, the scenario of multiple PD source separation based on PRPD are not yet effectively addressed. Fortunately, this issue is being addressed by feature extraction method based on time-domain analysis, combined with clustering algorithms.

\section{Equivalent TF Parameters}

With the development of high speed analog to digital converter, the researchers began to use the waveform to extract characteristics of the pulses, then used the clustering techniques to separate multiple discharge sources. Among them, the most widely used feature is the equivalent TF parameters proposed by Contin et al. [65], including equivalent time-length $T^{2}$ and equivalent bandwidth $W^{2}$. These parameters were defined as follows:

$$
\begin{gathered}
t_{0}=\sum_{i=0}^{N} t_{i} \cdot s\left(t_{i}\right)^{2} / \sum_{i=0}^{N} s\left(t_{i}\right)^{2} \\
T^{2}=\sum_{i=0}^{N}\left(t_{i}-t_{0}\right)^{2} s\left(x_{i}\right)^{2} / \sum_{i=0}^{N} s\left(x_{i}\right)^{2}
\end{gathered}
$$




$$
W^{2}=\sum_{i=0}^{N} f_{i}^{2} \cdot\left|X\left(f_{i}\right)\right|^{2} / \sum_{i=0}^{N}\left|X\left(f_{i}\right)\right|^{2}
$$

where $t_{0}$ is the time barycenter of the signal, $N$ is the sample number of a single PD pulse, $s\left(t_{i}\right)$ is the sample value at time $t_{i}$, and $X\left(f_{i}\right)$ is the frequency component at frequency $f_{i}$. Recently, experiment conducted by Mor et al. [97] indicated the sampling parameters have a significant impact on the TF parameters, $T^{2}$ increases with the sampling time, $W^{2}$ increases with the sampling frequency or sampling points, and high amplitude noise pose continuous challenge to accurate identification. In lieu of $T^{2}$ and $W^{2}$, they proposed to use current peak value Ipeak, apparent charge $Q$ and discharge energy $E$ to construct a new feature vector characterizing PD pulse. Test performed on models in the laboratory indicated the combination of any two of these three features obtained a good separation results, and this method is sampling parameters independent [71].

\section{Other TF Parameters}

Besides above approach, Contin and Pastore proposed to use normalized auto correlation function (NACF) which is good at summarizing both time and frequency dependent features of PD signals, to represent PD pulses in feature space. NACF was defined as:

$$
R_{s}(k)=\sum_{i=1}^{N} s(i) s(i+k) / \sum_{i=1}^{N} s(i)^{2}
$$

where $N$ is the sample number of a PD pulse, $s(i)$ is the $i_{\text {th }}$ sample. The test results clearly indicate an excellent performance on multiple PD source separation, with high noise tolerance [98]. However, the assumption that each PD pulse had an equal length, may not be right at all the time.

Zhu et al. [99] studied the application of other parameters in time and frequency domain for multiple PD source separation. These parameters include width, sharpness and gravity extracted from cumulative energy functions (CEs) and mathematical morphology gradients (MMGs) of CEs in both time and frequency domain. Experiments performed on artificial multi-defect models showed disturbances and PD pulses from different sources exhibited diverse features, and resulted in different clusters in feature space.

In [100], the authors proposed a feature extraction method based on the combination of S-transform (ST) and nonnegative matrix factorization (NMF)-based matrix decomposition. Firstly, they applied NMF on the ST amplitude matrix of each pulse to obtain a series of base vectors in the frequency domain and location vectors in the time domain. Then, a new group of features including sharpness, sum of derivatives, sparsity, entropy, mean value and standard deviation was extracted from the base and location vectors to construct a feature set. In addition, for a better cluster performance, NSGA-II was used to select optimal feature subset.

\section{Frequency Parameters}

In addition to the widely used TF features of PD pulses, Kuljaca et al. [101] extracted the amplitudes of three different frequencies from the FFT of each PD pulse, then exhibited them in 3D amplitude frequency space (AFS) to effectively separate sub-pattern corresponding to each PD source. However, due to space charge of proceeding discharge, the amplitudes of PD pulses from a typical source may not be the same. Therefore, for a better generalization ability, these amplitudes of each PD pulse should be normalized before clustering analysis.

The technique of choosing features by Kuljaca et al. was improved by Ardila et al. [102]. They divided the spectrum of each PD pulse into three frequency bands, and calculated the power ratio (PR) of the two higher band as the feature to perform clustering analysis. Further, they recently studied automatic selection of frequency bands for the PRs and introduced genetic algorithm to optimize the selection [103,104]. In [105], PR was adopted by Robles et al. to perform multi sources separation in substations and overhead lines PD monitoring successfully. Similar with that, Hao et al. [106] extracted 
energy ratio (ER) of six decomposition coefficients by 5-level DWT of each PD pulse which was then represented by a 6-dimensional ER feature. PCA further reduced the ER feature dimensionality from six to three. The test results showed an effective separation of multiple PD sources with robustness to noise.

\section{Signal Processing}

In addition to single pulse waveform, pulse waveform train was also employed by researchers for feature extraction. For example, Day et al. [82] applied CWT on detected noisy PD waveforms and that superposed on power frequency signal, then extracted the first seven statistical moments from cross-wavelet spectrum to form feature vector. Similarly, in the literature [107], the peak-time series measured by the peak detection technique was decomposed by wavelet packet transform (WPT) to nine levels. Then the first four statistical moments of the probability density function of the wavelet coefficients at all nine scales were extracted to form feature vectors. However, there is a significant drawback to the above method, which requires only one type of PD in the pulse train, thus the method is suitable for PD single source recognition rather than multi source separation.

\subsubsection{Summary}

Due to the wide application of PRPD in PD measurement and the independence on PD propagation effect of PRPD, the feature extraction method based on PRPD has been extensively studied and used in early stages, and a certain degree of success have been achieved in recognizing single PD type [68,86-93]. However, more than one PD source may exist within stator insulation system, which is not unusual in practical situations, and would be emerging simultaneously. Thus the feature extraction for multi PD source separation has become the most recently research hotspot. The scholars proposed a variety of feature extraction methods based on pulse waveform [65,97-107], which were proved to be promising in multi PD source separation by on-site testing as well as laboratory experiments. Table 6 summarizes feature extraction methods presented in this chapter, the corresponding reference is attached. Limited to length, this paper only summarized part of the new methods introduced during last decade, the earlier research work can be found in [108].

Table 6. Characteristics of PDs online measurement system for large generators.

\begin{tabular}{cccc}
\hline & Data Pattern & Technique/Feature & References \\
\hline & 2D PRPD profile & Statistical moments & {$[68,86,87,96]$} \\
2D PRPD profile & PCA, SNE & {$[88,89]$} \\
3D PRPD profile & PCA & {$[90]$} \\
PD distribution & Fractal parameters & {$[91,96]$} \\
& 3D PRPD image & 2D PCA & {$[92,93]$} \\
& 2D PRPD gray image & MSD & {$[94]$} \\
& 2D PRPD image & Weibull parameters & {$[95,96]$} \\
\hline PHA profile & Equivalent TF parameters & {$[65,97]$} \\
& Pulse waveform & Ipeak-Q-E & {$[71]$} \\
PD pulse & NACF & {$[98]$} \\
waveform & Pulse waveform & FFT, MMG & {$[99]$} \\
& Pulse waveform & ST, NMF & {$[100]$} \\
& Pulse waveform & FFT, PR & {$[101-105]$} \\
& Pulse waveform & DWT, PCA & {$[106]$} \\
& Pulse waveform & CWT & {$[82]$} \\
Waveform train & WPT & {$[107]$} \\
\hline
\end{tabular}

\subsection{Pattern Recognition}

After feature extraction, we are able to analyze PD signals based on both unsupervised and supervised pattern recognition techniques. Corresponding to two different categories of feature extraction methods, pattern recognition can be divided into single PD source classification (supervised learning) and multi PD sources clustering (unsupervised learning). Single PD source classification 
is a task to label PD source or type based on features extracted from PD distribution, which was the focus of previous research. The new goal of PD pattern recognition research had moved to clustering based on features extracted from PD pulse waveform to separate multiple PD sources occurring simultaneously. In general, clustering is used to separate different PD sources followed by classify each cluster to a typical PD source, as shown in Figure 8.

\subsubsection{Single PD Source Classification}

Classification is a common application of supervised learning, which refers to label PD type or source. Supervised learning consists of learning (training) and classifying (testing). The learning process aims at training classifier through sample data of different PD types (internal PD, slot PD, end-winding PD, VS and arcing etc.) which were obtained with artificial single defect models made in laboratory. After that, the classifying process determines the type of PD to which the unknown data belong. During last decade, researchers introduced different models for classifying PD signals. In this section, we introduce two popular techniques for PD source classification, i.e., neural network and support vector machine (SVM).

1. Neural Network

Neural network is a mathematical algorithm inspired by the central nervous systems of animals to perform distributed parallel computing [109]. A neural network usually composes of an input layer, at least one hidden layer and an output layer, as depicted in Figure 10a. The neurons are grouped in layers and are connected to all neurons of preceding and succeeding layers by different weights called synapses. The number of neurons in input layer relies on the number of input features extracted, while that of output layer depends on the number of defined classes [109], i.e., the number of PD types to be classified. Compared with other classifiers, neural networks has the capability to learn knowledge from training samples and store in synapses and neurons during training process [110]. The back propagation algorithm is the most frequently used method for the training process. During last decade, various neural network models had been developed for PD classification, such as back propagation neural network, probabilistic neural network, radial basis function network and ensemble neural network etc. In $[64,108,111]$, the authors reviewed these models exhaustively.

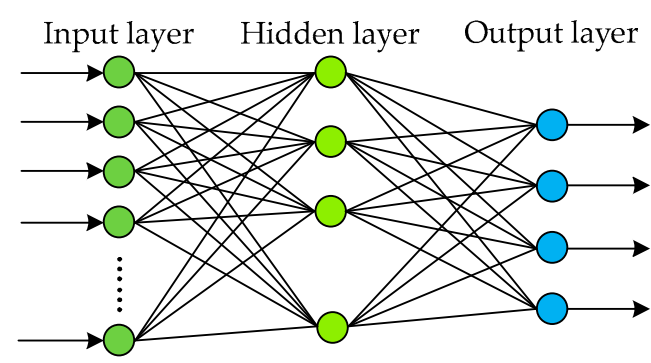

(a)

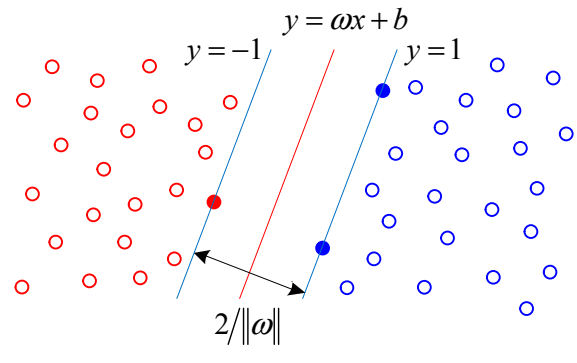

(b)

Figure 10. Structure of two types of classifiers, (a) NN with one hidden layer; (b) SVM [109].

Neural network is one of the most successful method used for PD pattern recognition. However, due to the complexity and decentrality of PDs in generators, neural networks have some drawbacks, including sensitive to initial weights, longer convergence time and prone to local minima. Although some intelligent algorithms such as genetic algorithm, have effectively solved the local minima problem, the reliance on user's experience to set network topology and weak generalizing capability are still the key factors hinder further generalization of neural network implementations. 


\section{SVM}

In order to face above problems, SVM was introduced for PD recognition recently. SVM is a supervised learning method developed from the limited samples statistical learning theory and structure risk minimization principle, which was originally designed for two-class classification problems by Vapnik in 1995 [109]. The basic principle of SVM is to map the original input space to higher dimensional space by kernel function, where an optimal hyperplane with maximal margin can be found to perform linear division of testing samples [112].

A linear two dimensional case of SVM for PD classification is portrayed in Figure 10b, in which the optimal hyperplane $y=\omega x+b$ distances from support vectors (solid circles) on critical decision boundaries $y=-1$ and $y=1$ with a maximum margin $1 /\|\omega\|$, where $x$ is the training data, $\omega$ is the normal vector of the hyperplane, $b$ is the bias parameter. Multiclass classification problems can be transformed into two-class classification problem by one-versus-the-rest and one-versus-one etc. encoding strategies [109]. SVM offers the advantage over other classification algorithms in small amount of sample, high dimensionality and nonlinear problems, thus encouraging in PD classification and achieved considerable focus and success over last decade [112-116].

SVM was firstly introduced into PD classification by Sanna et al. in 2004 [113]. In order to locate the insulation defect with respect to high voltage and low voltage electrodes, they extracted polarity and dissymmetry parameters from PD distributions followed by selection of most pivotal features through statistical analysis, and the result was then fed into three classifiers, including k-nearest neighbor, probabilistic neural network and SVM. SVM gave the best identification result of $78.4 \%$, and outperformed two others.

Along with Sanna et al., further studies have adopted SVM in PD classification. For example, Hao and Lewin [112] developed a PD recognition system based on SVM, where correlation analysis was applied to the PD pulse waveform reconstructed at the third level of 7-level sym decomposition for multi sources clustering. They simulated three artificial PD defects in laboratory. The $q_{a}-\varphi$ of each cluster formed the input features to the SVM. In addition, during the training and testing of SVM, data from conventional PD detector according to IEC 60270 and RFCT were used, respectively. The result indicated that the proposed PD recognition method was insensitive to the PD detection method. Further, Robles et al. [114] investigated the effectiveness of multiclass SVM for recognition of multi simultaneous PD sources include internal discharge, surface discharge and corona, using normalized PSD of each PD pulse as the input of SVM. The results indicated that multiclass SVM is highly effective in identifying PD for cases where several sources are active or when the SNR is low [114].

Notable recent advancement in SVM-based PD sources classification is the introduction of least square-SVM (LS-SVM) [115], fuzzy SVM (FSVM) [88] and particle swarm optimization VSM (PSO-SVM) [116]. LS-SVM differs from SVM by introducing the least square error as a loss function and thus avoid solving a quadratic programming problem while instead by solving a linear function [115]. FSVM is a variant of SVM and it is effective in handling data polluted by noise and disturbance. For FSVM, each data point hold a fuzzy weight and thus may make a contribution to optima hyperplane solving. Tests show FSVM significantly outperforms a number of ANN algorithms when conducted under well controlled condition in laboratory [88]. In [116], PSO was used to optimizing parameters of SVM classifier, then the PSO-SVM validated the effectiveness of the method proposed by the author, which was designed to eliminate disturbance and separate pulses from two simultaneous PD sources.

\subsubsection{Multi-PD Sources Clustering}

Recently, the goal of PD pattern recognition research has moved from the single source classification to multiple sources clustering, since the latter is most often encountered in insulation systems of large generators during operation. Many studies have been conducted in this regard, which are mainly based on features extracted by above time-domain analysis method attempting to group similar pulses into the same cluster to separate multi sources of PDs and disturbance [88,116]. 
This is usually done under the assumption that the same source generates pulses having similar shapes while pulses from different sources are characterized by different waveforms. The clustering algorithms commonly used in the PD pattern recognition include K-means, FCM and density-based spatial clustering of applications with noise (DBSCAN).

1. K-means

$\mathrm{K}$-means is an unsupervised learning algorithm used to automatically grouping data sets into $K$ clusters around centroids, by means of a distance measure, so that the inter-cluster similarity is maximized while that between different clusters is minimized [117]. $K$ is the number of desired clusters which can be defined based on priori knowledge or determined by a pre-processing method when lack of priori knowledge. The flowchart of K-means algorithm includes following steps.

- Step 1: Initialization of cluster centroids (means) $o_{k}$ randomly or following the method in [118].

- Step 2: Assign each data point to its nearest centroids to form $K$ clusters $C_{k}$.

- Step 3: Calculate the new centroids $o_{k}$ of each clusters $C_{k}$ and update as new cluster centroids.

- Step 4: Convergence judgment by the following Equation (11) [117].

$$
\underset{C}{\operatorname{argmin}} \sum_{k=1}^{K} \sum_{x_{n} \in C_{k}}\left\|x_{n}-o_{k}\right\|^{2}
$$

where $C$ is the cluster sets of $\left\{C_{1}, \ldots, C_{K}\right\}, x_{n}$ is the $n$th data point from all $N$ data points assigned to the $k_{\mathrm{th}}$ cluster $C_{k}, o_{k}$ is the centroid of the $k_{\mathrm{th}}$ cluster $C_{k}$. The two steps of assigning data points to clusters and computing the clusters means are repeated in turn until the Equation (11) converges or within defined limits, or some maximum number of iterations is exceeded.

With different features and distances, K-means was employed in multi PD sources clustering in $[98,104,119]$. In [98], Contin and Pastore applied K-means to separate and cluster pulses stemming from different sources while mixed with each other. They firstly introduced NACF as feature of PD pulses. Then adopted chord distance as the measure of distance between samples and centroids during K-means clustering. In addition, they performed quality check of clustering and then merged clusters with similar PD pattern. In [119], the author firstly extracted the statistical moments from PRPD pattern of four typical types of PD simulated in laboratory, then grouped these PD types into four to eight clusters according to Euclidean distance, and recommended using eight final clusters instead of four for better separation accuracy. In [104], PD pulses were represented by a feature vector with PRs of two frequency bands which were derived from FFT of PD pulse. In addition, the similarity between two pulses is measured by the Mahalanobis distance.

As an iterative optimization clustering algorithm, K-means is simple and effective. However, it is sensitive to initial centroids and outliers and prone to local minima, while only efficient in discovering clusters of spherical shape. In addition, there is no criterion for cluster number, i.e., PD sources number, determination, which may be a challenging task when lacking priori knowledge.

\section{FCM}

FCM is an extension of K-means by introducing fuzzy membership $p_{n k}$ into K-means to represent the degree of $x_{n}$ belonging to cluster $C_{k}$. In addition, the objective function of K-means in Equation (11) can be extended as follow for FCM [117]:

$$
\underset{P, C}{\operatorname{argmin}} \sum_{k=1}^{K} \sum_{n=1}^{N} p_{n k}^{m}\left\|x_{n}-o_{k}\right\|^{2}
$$

where $m>1$ is a free parameter chosen to adjust the blending of different clusters, $P=\left\{p_{n k}\right\}(1 \leq n \leq N$, $1 \leq k \leq K)$ is the cluster membership matrix, The probability of cluster membership for the point $x_{n}$ are normalized as $\sum_{k=1}^{K} p_{n k}=1$ where $p_{n k} \in[0,1]$. In general, the optimization of Equation (12) can be performed by gradient-based techniques [117]. 
In [100], Wang et al. employed NSGA-II to select the optimal features which are used to form the feature space, then FCM clustering was perform on the feature space to separate different PD sources. However, since FCM cannot provide the label information of each sample, it was applied to evaluate the performance of different feature subsets yet select the optimal features which are further used as input of SVM to realize the PD classification [92]. In [115], the authors also applied FCM to separate PD pulses based on equivalent TF parameters, which is followed by PD source recognition using LS-SVM.

Due to the introduction of fuzzy concept, FCM performs better in PD source clustering than its predecessor K-means. However, the fuzzy membership depends implicitly on the number of clusters. When the number of clusters is specified incorrectly, serious problems may arise. In addition, similar with K-means, FCM works well with data points distributed in spherical clusters of equal size, and is sensitive to initial centroids and outliers and prone to local minima. The parameter $m$ determines the degree of fuzziness of the final solution and of vital importance in noise reduction if is determined properly. Much work has been done to study the determination criterion for free parameter $m$, but it has not yet become practical theory.

\section{DBSCAN}

Differing from K-means and FCM, DBSCAN is a density rather than distance-based clustering algorithm [120]. Density of a given point $p$ is the number, $n$, of points in the $E_{p s}$ neighborhood of $p$, which is defined by $N_{E p s}(p)=\left\{q \in D \mid \operatorname{dist}(p, q) \leq E_{p s}\right\}$ where $D$ is the database of points, dist the function to calculate distance between points $p$ and $q . p$ is called a core point if $n$ greater than a minimum number, MinPts. $E_{p s}$ and MinPts are two parameters of the algorithm. In DBSCAN, all the points in $N_{E p s}(p)$ of core point $p$ are defined to be directly density reachable from $p$. If point $x$ is directly density reachable from point $y$, and $y$ is directly density reachable from point $z$, then $x$ is density reachable from $z$. Again, if points $x$ and $y$ are both density reachable from $z$, then $x$ and $y$ are density connected. DBSCAN generates a cluster from core point $p$ by covering all the points that are density connected to $p$ [120]. Once a cluster is identified, DBSCAN selects a new core point $q$ does not belong to any clusters formed previously, and repeats the above procedure to generate a new cluster. The iteration process terminates when no new point can be added to any cluster. Any point not contained by a cluster is classified as noise [120].

Due to its ability to distinguish noise as well as to discover clusters of arbitrary shapes, DBSCAN was employed as an efficient tool for PD signal clustering [99,101,106]. In [101], PD signals were projected into 3D AFS by selecting three different frequencies from the FFT of the signals. DBSCAN was then adopted to group the different clusters in 3D AFS. In [106], the authors performed PCA on 6 ERs vector of six decomposition coefficients from 5-level DWT, and reduced the feature dimensionality from six to three. DBSCAN was then adopted in the 3D principal components space to separate different PD sources. In [99], representative features were extracted from CEs and MMGs of CEs of PD signals and compose a 6-dimension feature space. Then improved DBSCAN was employed to separate the mixed PD signals into different sources.

DBSCAN outperform K-means in finding clusters with irregular shapes, and there is no need to predefine the number of clusters. However, compared with K-means, DBSCAN is inefficient when come to the case of high dimensionality clustering problem and the determination of $E_{p s}$ and MinPts is a complicated procedure which requires burdensome attempts.

\subsubsection{Summary}

In the last decade, tremendous progress has been made in PD pattern recognition. With an abundant of reliable PD data with identified source, supervised learning methods like Neural network and SVM had been widely attempted with considerable degree of success in classifying single PD source. However, it is a difficult task to obtain the PD data with labeled source in online application. On the other hand, the classification needs that the testing data characterizes just one PD source which, in turn, requires a reliable previous multi PD sources separation. The multi PD sources 
separation is the most recently research hotspot, much work had been done by combination features extracted from PD pulse waveform with unsupervised learning algorithms (clustering). In practical scenarios, single PD source classification and multi PD sources separation should work together to achieve better recognition of PD data, as shown in Figure 8. Research is on-going to find reliable ways of automatically determining the PD source based on the PD pulse waveform and PD distribution. Neural network, SVM, K-means, FCM and DBSCAN are popular. However, much work remains to validate the pattern recognition approaches before generator owners will widely adopt these methods for online and on-site application.

\section{Suggestions for Improvement}

Even if PD online measurement has recently been studied at the international level in various working groups under the umbrella of CIGRE [8], IEC [6,9] and IEEE [7]. It should be underlined that the development is going on, much more work has yet to be done in the future. For example, PD measurements are widely accepted and have been made on stator windings for over 40 years, there are still no agreed PD specifications for large generators where limits are defined, e.g., as acceptance criteria during commissioning test or operation diagnosis. In addition, automatic recognition and classification of complex PD signal associated with practical insulation systems of large generator stator winding continue to pose appreciable difficulty.

The basic difficulty in attempting to perform PD calibration and location is mainly the lack of an adequate mathematical model of stator winding to represent PD pulse propagation, which means that no methods exist for predicting the transient or frequency characteristics of a PD pulse as it appears at the terminals of the generator. The only available method of obtaining these characteristics is by experiment. However, extensive testing is needed by injecting pulses into different locations and the propagation characteristics are measured, which is practically impossible for all generators under monitoring. Consequently, it is of vital importance to build a mathematical model of the stator winding for PD signal propagation.

During last decade, PD online measurement was moved from periodic to continuous. However, to the best knowledge of the authors, most continuous PD online measurement systems for large generators are not really continuous, and very little work has been done on the real-time processing of PD signals. To this end, considering the slow evolving of insulation degrade and occasional of surge during operation, the measured PD data can be dealt with a hierarchical processing technique, which contains real-time supervision layer and holo-analytical layer, in real-time. Firstly, the variation of data bulk with respect to preceding data bulk was detected in real-time supervision layer. Based on the variation, decision was made on whether the data bulk should be saved for refined processing or not. Secondly, the saved data bulk was processed by holo-analytical layer, including denoising, feature extraction and pattern recognition for classifying the PD sources and then extracting PD trend parameters of each PD source and disturbance.

Previous PD source recognition techniques were mainly trained on artificial defect models in laboratory, which may not function well when put into practice in PD online measurement scenarios. This is mainly due to the complex propagation process of PD signal in stator windings. As we know, different PD will show typical dependency on operation and ambient condition of the generator as well as PD pattern. Thus, combining the PD pattern and relationship between PD type and operation and ambient condition, we can start to train the classifier online when a new PD source is separated by clustering algorithms reviewed above. With the hierarchical processing technique proposed above, it is feasible to gather the statistical PD pattern and relationship with operation or ambient condition parameters during the training period, for example a week. Finally, the new PD source was identified and added to the knowledge base. 


\section{Conclusions}

PD online measurement provides an important tool for assessing the insulation condition of the stator windings of large generators. In this paper, we have presented a comprehensive summary of the nature, form and characteristics of PD, as well the propagation characteristics of PD signal in stator windings. Following that, four main types of PD detection methods have been concisely elaborated. Various algorithms proposed for signal denoising, feature extraction and pattern recognition of PD signal have been described in adequate detail and attached with relevant references to avoid repetition of past work and to give a bird's eye view to fresh researchers in this area. The change in research focus of PD pattern recognition from single source classification to multi source separation was mentioned and reviewed in depth. Finally, certain suggestions were proposed to promote the application of PD online measurement in large generators, including building a mathematical model of stator winding, developing PD signal real-time processing techniques and PD source automatic identification approaches.

Acknowledgments: The authors thank China Yangtze Power Corporation for supporting this work. The authors would also like to thank anonymous referees for their comments and suggestions.

Author Contributions: The authors contributed equally to the reported research and writing of the paper.

Conflicts of Interest: The authors declare no conflict of interest.

\section{Abbreviations}

The following abbreviations are used in this manuscript:

PD Partial discharge

TEAM Thermal, electrical, ambient and mechanical

CIGRE International Council of Large Electric Systems

PRPD phase resolved partial discharge

HV High voltage

VS Vibration sparking

PHA Phase height analysis

HF High frequency

LF Low frequency

VHF Very high frequency

IEC International Electrotechnical Commission

IEEE Institute of Electrical and Electronic Engineers

RFCT Radio frequency current transformer

NCT Neutral RFCT coupling method

NCC Neutral capacitor coupling method

HVCC HV terminal capacitor coupling method

HVCT HV terminal RFCT coupling method

IPB Isolated phase output bus

SNR Signal to noise ratio

TF Time-frequency

WN White noise

DSI Discrete spectral interference

PPI Periodic pulse shaped interference

SPI stochastic pulse shaped interference

ADC analog to digital converter

FCM Fuzzy C-mean

IIR Infinite impulse response

PSD Power spectrum density

CWT Cross wavelet transform

DWT Discrete wavelet transform

WPT Wavelet packet transform 


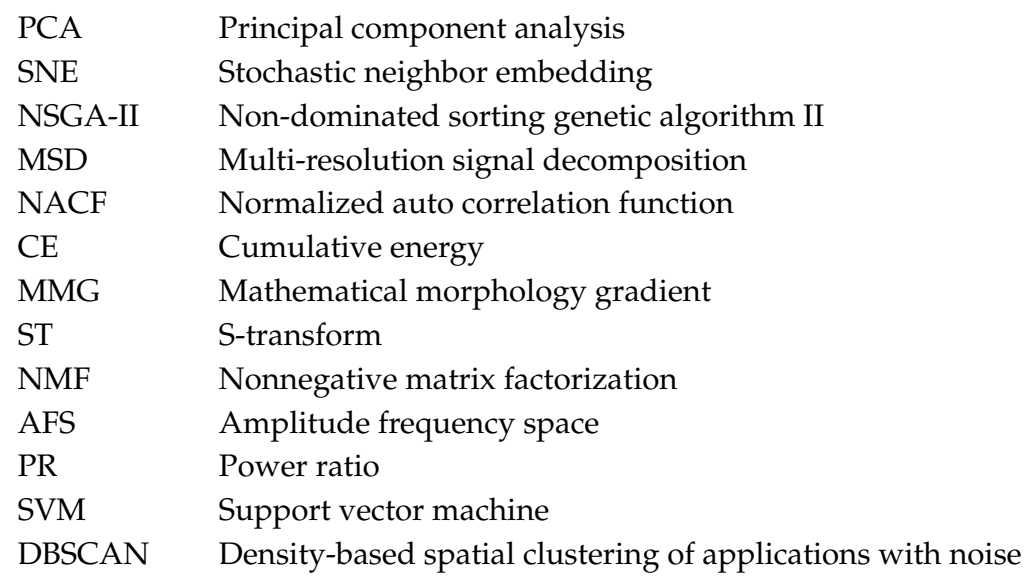

\section{References}

1. CIGRE WG A1.10. Survey of Hydrogenerator Failures; Cigre Report 392; CIGRE: Paris, France, 2009.

2. International Electrotechnical Commission. Evaluation and Qualification of Electrical Insulation Systems; IEC 60505; International Electrotechnical Commission: Geneva, Switzerland, 2011.

3. Stein, J.; Krikorian, M. HydroTrac: Continuous Partial Discharge Monitor for Hydrogenerators; EPRI: Palo Alto, CA, USA; New York Power Authority: White Plains, NY, USA, 2003.

4. Bartnikas, R. Partial discharges. Their mechanism, detection and measurement. IEEE Trans. Dielectr. Electr. Insul. 2002, 9, 763-808. [CrossRef]

5. Stone, G.C. Condition monitoring and diagnostics of motor and stator windings-A review. IEEE Trans. Dielectr. Electr. Insul. 2013, 20, 2073-2080. [CrossRef]

6. International Electrotechnical Commission. High-Voltage Test Techniques: Partial Discharge Measurements; IEC 60270; International Electrotechnical Commission: Geneva, Switzerland, 2015.

7. IEEE Standards Association. IEEE Guide for the Measurement of Partial Discharges in AC Electric Machinery; IEEE Std 1434 ${ }^{\mathrm{TM}}-2014$ (Revision of IEEE Std 1434-2000); IEEE Standards Association: Piscatawy, NJ, USA, 2014.

8. CIGRE WG D1.33. High-Voltage On-Site Testing with Partial Discharge Measurement; Cigre Report 502; CIGRE: Paris, France, 2012.

9. International Electrotechnical Commission. Rotating Electrical Machines-Part 27-2: On-Line Partial Discharge Measurements on the Stator Winding Insulation of Rotating Electrical Machines; IEC/TS 60034-27-2; International Electrotechnical Commission: Geneva, Switzerland, 2012.

10. Wu, M.; Cao, H.; Cao, J.; Nguyen, H.L.; Gomes, J.B. An overview of state-of-the-art partial discharge analysis techniques for condition monitoring. IEEE Electr. Insul. Mag. 2015, 31, 22-35. [CrossRef]

11. Sun, W.X. Study and Applications on the Method for Coordinate Monitoring of Generator Insulation. Ph.D. Thesis, Huazhong University of Science \& Technology, Wuhan, China, 2014.

12. CIGRE WG A1.40. Survey on Hydrogenerator Instrumentation and Monitoring; Cigre Report 682; CIGRE: Paris, France, 2017.

13. Stone, G.C. A perspective on online partial discharge monitoring for assessment of the condition of rotating machine stator winding insulation. IEEE Electr. Insul. Mag. 2012, 28, 8-13. [CrossRef]

14. Stone, G.C.; Letal, J.; Lloyd, B.A. Advancements in integrated generator rotor and stator condition monitoring. In Proceedings of the CIGRE Colloquium on Large Electrical Machines and Renewable Generation, Bucharest, Romania, 3-4 September 2013.

15. CIGRE WG A1.26. Guide for the Monitoring, Diagnosis and Prognosis of Large Motors; Cigre Report 558; CIGRE: Paris, France, 2013.

16. Johnson, J.S.; Warren, M. Detection of slot discharges in high-voltage stator windings during operation. Trans. Am. Inst. Electr. Eng. 1951, 70, 1998-2000. [CrossRef]

17. Montanari, G.C.; Cavallini, A. Partial discharge diagnostics: From apparatus monitoring to smart grid assessment. IEEE Electr. Insul. Mag. 2013, 29, 8-17. [CrossRef] 
18. Liese, M.; Brown, M. Design-dependent slot discharge and vibration sparking on high voltage windings. IEEE Trans. Dielectr. Electr. Insul. 2008, 15, 927-932. [CrossRef]

19. Brutsch, R.; Tari, M.; Frohlich, K.; Weiers, T. Insulation failure mechanisms of power generators. IEEE Electr. Insul. Mag. 2008, 24, 17-25. [CrossRef]

20. Stone, G.C.; Culbert, I.; Boulter, E.A.; Dhirani, H. Electrical Insulation for Rotating Machines: Design, Evaluation, Aging, Testing, and Repair, 2nd ed.; John Wiley \& Sons Inc.: Piscataway, NJ, USA, 2014; pp. 159-234.

21. Stone, G.C.; Maughan, C.V.; Nelson, D.; Schultz, R.P. Impact of slot discharges and vibration sparking on stator winding life in large generators. IEEE Electr. Insul. Mag. 2008, 24, 14-21. [CrossRef]

22. Maughan, C.V. Root-cause diagnostics of generator service failures. In Proceedings of the Conference Record of the 2004 IEEE International Symposium on Electrical Insulation (ISEI), Indianapolis, IN, USA, 19-22 September 2004; pp. 154-162.

23. Hudon, C.; Belec, M. Partial discharge signal interpretation for generator diagnostics. IEEE Trans. Dielectr. Electr. Insul. 2005, 12, 297-319. [CrossRef]

24. Timperley, J. Incipient fault identification through neutral RF monitoring of large rotating machines. IEEE Trans. Power Appar. Syst. 1983, PAS-102, 693-698.

25. Timperley, J. Identification of vibration sparking with EMI diagnostics. In Proceedings of the 76th Annual International Doble Client Conference, Boston, MA, USA, 29 April-3 May 2009.

26. Bartnikas, R.; Levi, J.H.E. A simple pulse height analyzer for partial discharge rate measurements. IEEE Trans. Instrum. Meas. 1969, 18, 341-345. [CrossRef]

27. Kelen, A. The Functional Testing of HV Generator Stator Insulation; CIGRE 15-03; CIGRE: Paris, France, 1976.

28. Holboll, J.T.; Henriksen, M. Partial discharge patterns related to surface deterioration in voids in epoxy. In Proceedings of the Conference Record of the 1990 IEEE International Symposium on Electrical Insulation, Toronto, ON, Canada, 3-6 June 1990; pp. 115-119.

29. Hudon, C.; Bélec, M.; Lévesque, M. Study of slot partial discharges in air-cooled generators. IEEE Trans. Dielectr. Electr. Insul. 2008, 15, 1675-1690. [CrossRef]

30. CIGRE Working Group. Report 21.03-Recognition of Discharges; ELECTRA No. 11; CIGRE: Paris, France; pp. 61-98.

31. Warren, V. Partial discharge testing: A progress report. In Proceedings of the Iris Rotating Machinery Conference, Santa Monica, CA, USA, 20-23 June 2011; pp. 1-17.

32. International Electrotechnical Commission. Rotating Electrical Machines_Part 27: Off-Line Partial Discharge Measurements on the Stator Winding Insulation of Rotating Electrical Machines; IEC 60034-27; International Electrotechnical Commission: Geneva, Switzerland, 2006.

33. Wilson, A.; Jackson, R.J.; Wang, N. Discharge detection techniques for stator windings. IEE Proc. Electr. Power Appl. 1985, 132, 234-244. [CrossRef]

34. Geary, R.; Kemp, I.J.; Wilson, A.; Wood, J.W. Towards improved calibration in the measurement of partial discharges in rotating machinery. In Proceedings of the Conference Record of the 1999 IEEE International Symposium on Electrical Insulation (ISEI), Toronto, Canada, 3-6 June 1990; pp. 141-144.

35. Zhou, C.; Kemp, I.J.; Allaa, M. The PD pulse behaviour in rotating machine stator windings. In Proceedings of the 1995 International Conference on Electrical Insulation and Dielectric Phenomena, Virginia Beach, VA, USA, 22-25 October 1995; pp. 372-375.

36. Tavner, P.J.; Jackson, R.J. Coupling of discharge currents between conductors of electrical machines owing to laminated steel core. IET Electr. Power Appl. 1988, 135, 295-307. [CrossRef]

37. Wood, J.W.; Sedding, H.G.; Hogg, W.K.; Kemp, I.J.; Zhu, H. Partial discharges in HV machines; initial considerations for a PD specification. IEE Proc. Sci. Meas. Technol. 1993, 140, 409-416. [CrossRef]

38. Qiong, L.; Jiang, J.G.; Tan, K.X.; Zeng, D.W. Experimental study of the pulse propagation in turbine generator stator windings. J. Tsinghua Univ. 1996, 7, 2-7.

39. Cheng, Y.C.; Li, C.R.; Wang, W. Research on propagation rule of partial discharge pulses inside generator along stator windings. Power Syst. Technol. 2005, 29, 65-70.

40. Pemen, A.J.M.; Laan, P.C.T.; Leeuw, W.D. Propagation of partial discharge signals in stator windings of turbine generators. IEEE Trans. Energy Convers. 2006, 21, 155-161. [CrossRef]

41. Henriksen, M.; Stone, G.C.; Kurtz, M. Propagation of partial discharge and noise pulses in turbine generators. IEEE Trans. Energy Convers. 1986, 3, 161-166. [CrossRef] 
42. Oslinger-Gutiérrez, J.L.; Muñoz-Muñoz, F.A.; Vanegas-Iriarte, J.A. Analysis of the partial discharge pulse propagation in the stator winding of a synchronous machine. DYNA 2015, 82, 62-69. [CrossRef]

43. Kemp, I.J.; Gupta, B.K.; Stone, G.C. Calibration difficulties associated with partial discharge detectors in rotating machine applications. In Proceedings of the 18th Conference on Electrical and Electronic Insulation, Chicago, IL, USA, 5-8 October 1987; pp. 92-97.

44. Harrold, R.T.; Emery, F.T.; Murphy, F.J.; Murphy, F.J.; Drinkut, S.A. Radio frequency sensing of incipient arcing faults within large turbine generators. IEEE Trans. Power Appar. Syst. 1979, PAS-98, 1167-1173. [CrossRef]

45. Binder, E.; Draxler, A.; Egger, H. Developments and Verification Tests of Diagnosis Methods for Hydro-Generators; CIGRE 11-301; CIGRE: Paris, France, 2000.

46. $\mathrm{Su}, \mathrm{Q}$. Partial discharge measurements on generators using a noise gating system. In Proceedings of the Australasian Universities Power Engineering Conference, Darwin, Australia, 26-29 September 1999.

47. Mohammed, O.A.; Mundulas, J. Improvements in RF monitoring system on generators. IEEE Trans. Energy Convers. 1989, 4, 237-243. [CrossRef]

48. Grunewald, P.; Weidner, J. Possibilities and Experience with Off and On-Line Diagnosis of Turbine Generator Stator Winding Insulations; CIGRE 11-206; CIGRE: Paris, France, 1994.

49. Kurtz, M.; Lyles, J.F.; Stone, G.C. Application of partial discharge testing to hydro generator maintenance. IEEE Trans. Power Appar. Syst. 1984, PAS-103, 2148-2157. [CrossRef]

50. Johnson, J.S. A maintenance inspection program for large rotating machines. Trans. Am. Inst. Electr. Eng. 1951, 70, 749-755. [CrossRef]

51. Stone, G.C.; Sasic, M. Twenty-five years of experience with on-line partial discharge testing of stator winding. In Proceedings of the 12th International Conference on Electrical Insulation, Birmingham, UK, 29-31 May 2013; pp. 152-157.

52. Binder, E.; Draxler, A.; Egger, H. Experience with On-Line and Off-Line PD Measurements of Generators; CIGRE 15-106; CIGRE: Paris, France, 1998.

53. Timperley, J.E. Comparison of PDA and EMI diagnostic measurements. In Proceedings of the Conference Record of the 2002 IEEE International Symposium on Electrical Insulation, Boston, MA, USA, 7-10 April 2002; pp. 575-578.

54. Zhu, H.; Green, V.; Sasic, M.; Halliburton, S. Increased sensitivity of capacitive couplers for in-service PD measurement in rotating machines. IEEE Trans. Energy Convers. 1999, 14, 1184-1192. [CrossRef]

55. Campbell, S.R.; Stone, G.C.; Sedding, H.G.; Klempner, G.S.; McDermid, W.; Bussey, R.G. Practical on-line partial discharge tests for turbine generators and motors. IEEE Trans. Energy Convers. 1994, 9, 281-287. [CrossRef]

56. Zhou, Y.; Qin, Y.; Leach, C. Cost-effective online partial discharge measurements for electrical machines: Preventing insulation failure. IEEE Electr. Insul. Mag. 2010, 5, 23-29. [CrossRef]

57. Berlijn, S.; Markalous, S.; Strom, K. Web-based PD monitoring of a generator in Loforsen Sweden. In Proceedings of the 2008 International Conference on Condition Monitoring and Diagnosis, Beijing, China, 21-24 April 2008; pp. 167-170.

58. Wendel, C.; Stephan, C.E.; Peters, M.; Stein, R.; Joho, R. Automatic PD Pattern Evaluation as Part of a Condition Based Maintenance Strategy; CIGRE A1-213; CIGRE: Paris, France, 2006.

59. Omicron. MONGEMO-Brochure-ENU. Available online: https://www.omicronenergy.com/en/download/ document/0C8EBB2A-65C1-46EE-A95D-39583E4A0DB2/ (accessed on 9 October 2017).

60. HVPD. HVPD_Longshot_4-Page_Product_Card. Available online: http://www.hvpd.co.uk/files/6114/ 8223/3674/HVPD_Longshot_4-Page_Product_Card.pdf (accessed on 9 October 2017).

61. Fornasari, L.; Montanari, G.C.; Cavallini, A. Alarm management in permanent PD monitoring for generators. In Proceedings of the Conference Record of the 2012 IEEE International Symposium on Electrical Insulation (ISEI), San Juan, PR, USA, 10-13 June 2012; pp. 571-575.

62. Gross, D.W. Partial discharge measurement and monitoring on rotating machines. In Proceedings of the Conference Record of the 2002 IEEE International Symposium on Electrical Insulation, Boston, MA, USA, 7-10 April 2002; pp. 570-574.

63. Stone, G. Importance of bandwidth in PD measurement in operating motors and generators. IEEE Trans. Dielectr. Electr. Insul. 2000, 7, 6-11. [CrossRef] 
64. Raymond, W.J.K.; Illias, H.A.; Mokhlis, H. Partial discharge classifications: Review of recent progress. Measurement 2015, 68, 164-181. [CrossRef]

65. Contin, A.; Cavallini, A.; Montanari, G.C.; Pasini, G.; Puletti, F. Digital detection and fuzzy classification of partial discharge signals. IEEE Trans. Dielectr. Electr. Insul. 2002, 9, 335-348. [CrossRef]

66. Satish, L.; Nazneen, B. Wavelet-based denoising of partial discharge signals buried in excessive noise and interference. IEEE Trans. Dielectr. Electr. Insul. 2003, 10, 354-367. [CrossRef]

67. Li, J.; Jiang, T.Y.; Grzybowski, S.; Cheng, C.K. Scale dependent wavelet selection for de-noising of partial discharge detection. IEEE Trans. Dielectr. Electr. Insul. 2010, 17, 1705-1714. [CrossRef]

68. Gulski, E.; Kreuger, F.H. Computer-aided recognition of discharge sources. IEEE Electr. Insul. Mag. 1992, 27, 82-92. [CrossRef]

69. Van Brunt, R.J.; Cernyar, E.W.; Von Glahn, P. Importance of unraveling memory propagation effects in interpreting data on partial discharge statistics. IEEE Trans. Electr. Insul. 1993, 28, 905-916. [CrossRef]

70. Sedding, H.G.; Klempner, G.; Kapler, J.; Campbell, S.R.; Stone, G.C.; Kingsley, A. A New On-Line Partial Discharge Test for Turbine Generators; CIGRE 11-303; CIGRE: Paris, France, 1992.

71. Mor, A.R.; Heredia, L.C.C. New clustering techniques based on current peak value, charge and energy calculations for separation of partial discharge sources. IEEE Trans. Dielectr. Electr. Insul. 2017, 24, 340-348. [CrossRef]

72. Luo, X.; Niu, H.; Wu, J. A modified method of suppressing narrow-band interference using FFT power spectrum. In Proceedings of the Conference Record of the 2013 IEEE International Conference on Solid Dielectrics (ICSD), Bologna, Italy, 30 June-4 July 2013; pp. 83-87.

73. Nagesh, V.; Gururaj, B.I. Evaluation of digital filters for rejecting discrete spectral interference in on-site PD measurements. IEEE Trans. Electr. Insul. 1993, 28, 73-85. [CrossRef]

74. Sher, Z.K.; Zhu, D.H.; Jin, X.H.; Tan, K.X. A new adaptive technique for on-line partial discharge monitoring. IEEE Trans. Dielectr. Electr. Insul. 1995, 2, 700-707. [CrossRef]

75. Ma, X.; Zhou, C.; Kemp, I.J. Automated wavelet selection and thresholding for PD detection. IEEE. Electr. Insul. Mag. 2002, 18, 37-45. [CrossRef]

76. Chan, J.C.; Ma, H.; Saha, T.K.; Chandima, E. A novel level-based automatic wavelet selection scheme for partial discharge measurement. In Proceedings of the 2012 Power Engineering Conference (AUPEC), Bali, Indonesia, 26-29 September 2012; pp. 1-6.

77. Altay, Ö.; Kalenderli, Ö. Wavelet base selection for de-noising and extraction of partial discharge pulses in noisy environment. IET Sci. Meas. Technol. 2014, 9, 276-284. [CrossRef]

78. Carvalho, A.T.; Lima, A.C.S.; Cunha, C.F.F.C. Identification of partial discharges immersed in noise in large hydro-generators based on improved wavelet selection methods. Measurement 2015, 75, 122-133. [CrossRef]

79. Cunha, C.F.F.C.; Carvalho, A.T.; Petraglia, M.R.; Lima, A.C.S. A new wavelet selection method for partial discharge denoising. Electr. Power Syst. Res. 2015, 125, 184-195. [CrossRef]

80. Zhang, H.; Blackburn, T.R.; Phung, B.T. A novel wavelet transform technique for on-line partial discharge measurements. 2. On-site noise rejection application. IEEE Trans. Dielectr. Electr. Insul. 2007, 14, 15-22. [CrossRef]

81. Xie, Y.B.; Tang, J.; Zhang, X.X. Suppressing white-noise in partial discharge measurements part 2: The optimal denoising scheme. Eur. Trans. Electr. Power 2010, 20, 811-821. [CrossRef]

82. Dey, D.; Chatterjee, B.; Chakravorti, S.; Munshi, S. Cross-wavelet transform as a new paradigm for feature extraction from noisy partial discharge pulses. IEEE Trans. Dielectr. Electr. Insul. 2010, 17, 157-166. [CrossRef]

83. Chan, J.C.; Ma, H.; Saha, T.K.; Ekanayake, C. Self-adaptive partial discharge signal de-noising based on ensemble empirical mode decomposition and automatic morphological thresholding. IEEE Trans. Dielectr. Electr. Insul. 2014, 21, 294-303. [CrossRef]

84. Majidi, M.; Fadali, M.S.; Etezadi-Amoli, M.; Oskuoee, M. Partial discharge pattern recognition via sparse representation and ANN. IEEE Trans. Dielectr. Electr. Insul. 2015, 22, 1061-1070. [CrossRef]

85. Sriram, S.; Nitin, S.; Prabhu, K.M.M.; Bastiaans, M.J. Signal denoising techniques for partial discharge measurements. IEEE Trans. Dielectr. Electr. Insul. 2005, 12, 1182-1191. [CrossRef]

86. Okamoto, T.; Tanaka, T. Novel partial discharge measurement computer-aided measurement systems. IEEE Trans. Electr. Insul. 1986, EI-21, 1015-1019. [CrossRef] 
87. Mas'ud, A.A.; Stewart, B.G.; McMeekin, S.G. An investigative study into the sensitivity of different partial discharge $\varphi$-q-n pattern resolution sizes on statistical neural network pattern classification. Measurement 2016, 92, 497-507. [CrossRef]

88. Ma, H.; Chan, J.C.; Saha, T.K.; Ekanayake, C. Pattern recognition techniques and their applications for automatic classification of artificial partial discharge sources. IEEE Trans. Dielectr. Electr. Insul. 2013, 20, 468-478. [CrossRef]

89. Lai, K.X.; Phung, B.T.; Blackburn, T.R. Application of data mining on partial discharge part I: Predictive modelling classification. IEEE Trans. Dielectr. Electr. Insul. 2010, 17, 846-854. [CrossRef]

90. Raymond, W.J.K.; Illias, H.A.; Bakar, A.H.A. High noise tolerance feature extraction for partial discharge classification in XLPE cable joints. IEEE Trans. Dielectr. Electr. Insul. 2017, 24, 66-74. [CrossRef]

91. Satish, L.; Zaengl, W.S. Can fractal features be used for recognizing 3-d partial discharge patterns. IEEE Trans. Dielectr. Electr. Insul. 1995, 2, 352-359. [CrossRef]

92. Wang, K.; Li, J.; Zhang, S.; Gao, F.; Cheng, H.C.; Liu, R.; Liao, R.J.; Grzybowski, S. A new image-oriented feature extraction method for partial discharges. IEEE Trans. Dielectr. Electr. Insul. 2015, 22, 1015-1024. [CrossRef]

93. Zhang, S.; Li, C.R.; Wang, K.; Li, J.Z. Improving recognition accuracy of partial discharge patterns by image-oriented feature extraction and selection technique. IEEE Trans. Dielectr. Electr. Insul. 2016, 23, 1076-1087. [CrossRef]

94. Lalitha, E.M.; Satish, L. Wavelet analysis for classification of multi-source PD patterns. IEEE Trans. Dielectr. Electr. Insul. 2000, 7, 40-47. [CrossRef]

95. Cacciari, M.; Contin, A.; Montanari, G.C. Use of a mixed-Weibull distribution for the identification of PD phenomena. IEEE Trans. Dielectr. Electr. Insul. 1995, 2, 614-627. [CrossRef]

96. Candela, R.; Mirelli, G.; Schifani, R. PD recognition by means of statistical and fractal parameters and a neural network. IEEE Trans. Dielectr. Electr. Insul. 2000, 7, 7-94. [CrossRef]

97. Mor, A.R.; Heredia, L.C.C. Effect of acquisition parameters on equivalent time and equivalent bandwidth algorithms for partial discharge clustering. Int. J. Electr. Power Energy Syst. 2017, 88, 141-149.

98. Contin, A.; Pastore, S. Classification and separation of partial discharge signals by means of their auto-correlation function evaluation. IEEE Trans. Dielectr. Electr. Insul. 2009, 16, 1609-1622. [CrossRef]

99. Zhu, M.X.; Zhang, J.N.; Li, Y.; Wei, Y.H.; Deng, J.B.; Mu, H.B.; Zhang, G.H.; Shao, X.J. Partial discharge signals separation using cumulative energy function and mathematical morphology gradient. IEEE Trans. Dielectr. Electr. Insul. 2016, 23, 482-493. [CrossRef]

100. Wang, K.; Liao, R.; Yang, L.; Li, J. Optimal features selected by NSGA-II for partial discharge pulses separation based on time-frequency representation and matrix decomposition. IEEE Trans. Dielectr. Electr. Insul. 2013, 20, 825-838. [CrossRef]

101. Kuljaca, N.; Meregalli, S.; Contin, A.; Ukovich, A. Separation of multiple sources in PD measurements using an amplitude-frequency relation diagram. In Proceedings of the 10th IEEE International Conference on Solid Dielectrics (ICSD), Potsdam, Germany, 4-9 July 2010; pp. 1-4.

102. Ardila-Rey, J.A.; Martínez-Tarifa, J.M.; Robles, G. Partial discharge and noise separation by means of spectral power clustering techniques. IEEE Trans. Dielectr. Electr. Insul. 2013, 20, 1436-1443. [CrossRef]

103. Ardila-Rey, J.A.; Albarracín, R.; Álvarez, F.; Barrueto, A. A validation of the spectral power clustering technique (SPCT) by using a Rogowski coil in partial discharge measurements. Sensors 2015, 15, 25898-25918. [CrossRef] [PubMed]

104. Fresno, J.M.; Ardila-Rey, J.A.; Martínez-Tarifa, J.M.; Robles, G. Partial discharges and noise separation using spectral power ratios and genetic algorithms. IEEE Trans. Dielectr. Electr. Insul. 2017, 24, 31-38. [CrossRef]

105. Robles, G.; Fresno, J.M.; Martínez-Tarifa, J.M. Separation of radio-frequency sources and localization of partial discharges in noisy environments. Sensors 2015, 15, 9882-9898. [CrossRef] [PubMed]

106. Hao, L.; Lewin, P.L.; Hunter, J.A.; Swaffield, D.J. Discrimination of multiple PD sources using wavelet decomposition and principal component analysis. IEEE Trans. Dielectr. Electr. Insul. 2011, 8, 1702-1711. [CrossRef]

107. Evagorou, D.; Kyprianou, A.; Lewin, P.L.; Stavron, A.; Efthymiou, V.; Metaxas, A.C.; Georghiou, G.E. Feature extraction of partial discharge signals using the wavelet packet transform and classification with a probabilistic neural network. IET Sci. Meas. Technol. 2010, 4, 177-192. [CrossRef] 
108. Sahoo, N.C.; Salama, M.M.A.; Bartnikas, R. Trends in partial discharge pattern classification: A survey. IEEE Trans. Dielectr. Electr. Insul. 2005, 12, 248-264. [CrossRef]

109. Bishop, C.M. Pattern Recognition and Machine Learning; Springer: New York, NY, USA, 2006; pp. $326-339$.

110. Mas'ud, A.A.; Ardila-Rey, J.A.; Albarracín, R.; Muhammad-Sukki, F.; Bani, N.A. Comparison of the performance of artificial neural networks and fuzzy logic for recognizing different partial discharge sources. Energies 2017, 10, 1060. [CrossRef]

111. Mas'ud, A.A.; Albarracín, R.; Ardila-Rey, J.A.; Muhammad-Sukki, F.; Illias, H.A.; Bani, N.A.; Munir, A.B. Artificial neural network application for partial discharge recognition: Survey and future directions. Energies 2016, 9, 574. [CrossRef]

112. Hao, L.; Lewin, P.L. Partial discharge source discrimination using a support vector machine. IEEE Trans. Dielectr. Electr. Insul. 2010, 17, 189-197. [CrossRef]

113. Poyhonen, S.; Conti, M.; Cavallini, A.; Montanari, G.C.; Filippettis, F. Insulation defect localization through partial discharge measurements and numerical classification. In Proceedings of the Conference Record of 2004 IEEE International Symposium on Industrial Electronics, Ajaccio, France, 4-7 May 2004; pp. 417-422.

114. Robles, G.; Parrado-Hernández, E.; Ardila-Rey, J.; Martinez-Tarifa, J.M.M. Multiple partial discharge source discrimination with multiclass support vector machines. Expert Syst. Appl. 2016, 55, 417-428. [CrossRef]

115. Si, W.R.; Li, J.H.; Peng, Y.; Li, Y.M. Digital detection, grouping and classification of partial discharge signals at DC voltage. IEEE Trans. Dielectr. Electr. Insul. 2008, 15, 1663-1674.

116. Wang, K.; Li, J.Z.; Zhang, S.Q.; Liao, R.J.; Wu, F.F.; Yang, L.J.; Li, J.; Grzybowski, S.; Yan, J.M. A hybrid algorithm based on s transform and affinity propagation clustering for separation of two simultaneously artificial partial discharge sources. IEEE Trans. Dielectr. Electr. Insul. 2015, 22, 1042-1060. [CrossRef]

117. Duda, R.O.; Hart, P.E.; Stork, D.G. Unsupervised Learning and Clustering. In Pattern Classification; Wiley: New York, NY, USA, 1973; Chapter 10; pp. 13-16.

118. Hartigan, J.A.; Wong, M.A. Algorithm AS 136: A k-means clustering algorithm. J. R. Stat. Soc. C 1979, 28, 100-108. [CrossRef]

119. Chatpattananan, V.; Pattanadech, N.; Yutthagowith, P. Partial discharge classification on high voltage equipment with K-means. In Proceedings of the 8th International Conference on Properties and applications of Dielectric Materials, Bali, Indonesia, 26-30 June 2006; pp. 191-194.

120. Ester, M.; Kriegel, H.P.; Sander, J.; Xu, X. A density-based algorithm for discovering clusters in large spatial databases with noise. In Proceedings of the Second International Conference on Knowledge Discovery and Data Mining, Portland, OR, USA, 2-4 August 1996; pp. 226-231. 